\title{
Autonomy and the Folk Concept of Valid Consent
}

\author{
Joanna Demaree-Cotton \\ (Yale University) \\ Roseanna Sommers \\ (University of Michigan)
}

This is an Accepted Manuscript version of an article published by Elsevier in Cognition.

\begin{abstract}
Consent governs innumerable everyday social interactions, including sex, medical exams, the use of property, and economic transactions. Yet little is known about how ordinary people reason about the validity of consent. Across the domains of sex, medicine, and police entry, Study 1 showed that when agents lack autonomous decision-making capacities, participants are less likely to view their consent as valid; however, failing to exercise this capacity and deciding in a nonautonomous way did not reduce consent judgments. Study 2 found that specific and concrete incapacities reduced judgments of valid consent, but failing to exercise these specific capacities did not, even when the consenter makes an irrational and inauthentic decision. Finally, Study 3 showed that the effect of autonomy on judgments of valid consent carries important downstream consequences for moral reasoning about the rights and obligations of third parties, even when the consented-to action is morally wrong. Overall, these findings suggest that laypeople embrace a normative, domain-general concept of valid consent that depends consistently on the possession of autonomous capacities, but not on the exercise of these capacities. Autonomous decisions and autonomous capacities thus play divergent roles in moral reasoning about consent interactions: while the former appears relevant for assessing the wrongfulness of consented-to acts, the latter plays a role in whether consent is regarded as authoritative and therefore as transforming moral rights.
\end{abstract}

\section{Keywords:}

consent; moral reasoning; autonomy; ownership; moral psychology; experimental philosophy

\section{Introduction}

Consent is morally transformative and suffuses our everyday moral and social lives. Valid consent makes the difference between permissible sex and rape; between a medical exam and assault; between entering a person's home and trespass; between an economic transaction and theft. We need consent to include participants in research, to collect private information, to borrow things, to exchange money, to perform medical procedures, to cut someone's hair, and to enter into legally binding contracts. The importance of consent is reflected in extensive treatments of valid consent in moral philosophy and the law, as well as in biomedical ethics and psychiatry (Beauchamp \& Childress, 2013; Faden \& Beauchamp, 1986; Appelbaum \& Roth, 1982).

These fields emphasize that a person who assents - for example, by saying "yes"- does not necessarily give morally transformative or legally valid consent. For instance, most philosophers, legal scholars and medical ethicists do not consider the assent of people who are coerced, under duress, severely intoxicated, underage, intellectually disabled, or otherwise incapacitated to constitute valid consent (Beauchamp \& Childress, 2013, Chapter 3; 
Dougherty, 2019; Hurd, 1996; Pugh, 2020; Wertheimer, 2003). Thus, the received view in these fields is that consent is valid only if it is autonomous (Beauchamp, 2010).

Yet, the idea that consent must be autonomous is inherently ambiguous. It could mean that the consenter must be autonomous in the sense of having the capacity to make autonomous decisions. Alternatively, it could mean that the consenter must exercise this capacity and in fact make an autonomous decision. Note that one can possess a capacity, though one does not exercise it. Thus, someone might possess the mathematical capacity to work out the answer to " 24 x 7," but that doesn't mean they will exercise it: perhaps, instead of working out the answer, they might simply guess. Similarly, a competent adult can possess the capacity to engage in autonomous decision-making, but their decision to consent could fail to be autonomous if they don't exercise this capacity: they could act whimsically or impulsively; give in to a fleeting emotional reaction; not think things through properly; or give in to pressure from others to say 'yes' to something they don't really want to do.

The present studies address the understudied question of how people reason about the validity of consent by investigating whether autonomy plays an important role in ordinary reasoning, and, if so, in what sense consent must be autonomous for it to be considered valid and thus morally transformative. Specifically, must consent be the product of exercising autonomous decision-making capacities (that is, be the product of rational and authentic processes)? Or is it sufficient for consent to be given by an agent who possesses autonomous decision-making capacities, even if they fail to exercise these capacities, resulting in a decision that may be neither rational nor what the agent really wants?

Surprisingly little is known about how ordinary people reason about valid consent, including its relationship to autonomy. Despite the pervasive importance of consent to social life, its role in moral cognition has been relatively understudied. While ample social science research investigates how people communicate about consent through both verbal and nonverbal means (e.g. Beres, 2014; Wignall, Stirling \& Scoats, 2020), and how people reason about violations involving nonconsensual interactions, as when a person verbally objects (e.g. Gravelin, Biernat, \& Bucher, 2019; Hammond, Berry, \& Rodriguez, 2011; Niemi \& Young, 2016; Peace \& Valois, 2014; Whatley, 1996; Yndo \& Zawacki, 2020; see Muehlenhard et al., 2016, for an overview of social scientific research on sexual consent), few studies have investigated the factors that underlie ordinary judgments concerning whether consent is valid. Moreover, much of the existing psychological research on consent examines specialized topics-most prominently, sexual consent (e.g. Beres, 2014; Jozkowski et al., 2014) and informed consent (Bohns, in press) - rather than investigating consent as a domain-general moral concept. Put simply, while much work in contemporary moral psychology has focused on when "no" is taken to mean "no," little research has focused on when "yes" is taken to mean "yes."

One exception is Sommers (2020). Sommers asked participants to evaluate scenarios describing agents who give consent only because they have been intentionally deceived about important facts (e.g., an agent gives sexual consent after the partner lies to them about not having HIV; a buyer signs a sales contract after the seller lies about the product). Surprisingly - and in contrast to treatments of deception in moral philosophy (Dougherty, 2013) and the law (Blum et al., 2021) according to which deception vitiates consent-Sommers found that participants tend to judge that such interactions are consensual across a variety of contexts. This finding raises the possibility that the ordinary concept of valid consent, and its role in moral reasoning, may deviate starkly from academic treatments. 
Studying consent judgments is important for several reasons. First, prior theorizing suggests that judgments of valid consent should play an important role in moral reasoning. Literature in philosophy, law, and bioethics suggest that valid consent is normally required for interactions with other people's lives, bodies, or property to be considered permissible. For instance, it's very morally wrong to have sex with someone without their valid consent. Moral philosophy and legal theory explain the importance of consent in terms of transformation: valid consent transforms moral rights and corresponding obligations (Hohfeld, 1913; Hurd, 1996). For instance, if $\mathrm{A}$ gives valid consent to sex with $\mathrm{B}$, then $\mathrm{A}$ (temporarily) waives their autonomy-based right to not be touched by $\mathrm{B}$ in this manner, and $\mathrm{B}$ is no longer under a corresponding moral obligation to refrain from having sex with A. Consequently, if B has sex with A, they don't wrong A in virtue of violating this right. Of course, consensual sex can be considered wrong or inappropriate for other reasons, such as adultery or incest (e.g. Haidt, Bjorklund, \& Murphy, 2000; Lim and Roloff, 1999). But consent is considered a necessary element for sex to be morally permissible. Furthermore, the granting of valid consent is thought to affect the allocation of other rights and obligations, including those of innocent third parties. For instance, whether or not police are obligated to arrest someone for sexual assault should depend crucially on the validity of the sexual partner's consent - not, for instance, on the moral wrongness of violating moral norms against adultery. Thus, the ordinary concept of valid consent may play an important role in reasoning about moral permissions and moral rights.

Second, ordinary reasoning about consent is likely to have practical implications for consent policy in areas such as law, medicine, and educational campaigns (e.g., Beres, 2014; Humphreys \& Herold, 2003; Marg, 2020). If people's ordinary concept of valid consent misaligns with expert treatments and official policy, it may make it more likely that people misunderstand, misapply, or simply disagree with policy, with implications for compliance and trust in institutions that uphold these policies (Hosmer, 1995; Humphreys \& Herold, 2003; see also discussion in Muehlenhard et al., 2016).

Thirdly, the folk conception of consent may carry legal ramifications. Legal scholarship and practice rely on understanding the "ordinary meaning" of legally relevant concepts, including consent; thus there is increasing interest in the contribution of the cognitive scientific study of ordinary concepts to legal theory in the emerging field of "experimental jurisprudence" (Struchiner, Hannikainen, \& de Almeida, 2020; Tobia, 2022, forthcoming). Additionally, ethical attitudes influence juror verdicts (e.g. Peter-Hagene \& Ratliff, 2020), juries are empowered to decide whether valid consent has been granted in legal cases (Kahan, 2010; Rerick, Livingston, \& Davis, 2019).

\subsection{Prior empirical work on consent and moral rights}

While few studies have investigated the folk concept of valid consent, prior psychological research on adjacent concepts, such as ownership, suggests that consent may play an important role in moral reasoning about people's rights and obligations. For example, when people attribute ownership of an object, they first determine whether it was acquired consensually (e.g., through purchasing it or receiving it as a gift) or non-consensually (e.g., by stealing), and only in the former cases do they judge the possessor to be the owner of the object (Friedman, Neary, Defeyter \& Malcolm, 2011). Once ownership is established, people infer certain rights over the object, such as the right to keep it or the right to determine what happens to it. From age 3, children discern that consent is important for determining ownership: they assume that the person who forbids (or allows) others to use an object by withholding (or 
giving) permission is the owner of the object (Neary, Friedman, \& Burnstein, 2009). Correspondingly, non-owners are morally obliged to refrain from using an object owned by someone else (Neary, Friedman, \& Burnstein, 2009), taking it, or destroying it (Millar, Turri, and Friedman, 2014) — unless they have the owner's consent. Similarly, if Jack protests against Tom playing with a toy, children object to Jack's interference if the owner had given Tom permission. Thus, children appear to think that consent affects whether or not a third party may interfere (Schmidt, Rakozcy \& Tomasello, 2013).

The foregoing research suggests that ownership rights are allocated as a function of consent, but whether such allocations are affected by the validity of the consent has not been directly investigated. If an owner grants permission in a non-autonomous fashion, will people still draw inferences about people's rights to use or interfere with the property?

\subsection{The role of autonomy in judgments of valid consent: Two hypotheses}

The concept of autonomy has been studied in the context of psychological wellbeing (Deci \& Ryan, 2009) and it has received widespread attention in the study of moral cognition: perceptions of autonomy play an important role in folk reasoning about moral responsibility (Feltz \& Cova, 2014), free will (Vonasch, Baumeister, \& Mele, 2018), ownership (Starmans and Friedman, 2016), and rights of personal choice (Nucci \& Lee, 1993). More generally, autonomy-based reasoning may capture a distinct and cross-cultural domain of moral thought (Graham et al, 2013; Neff, 2001; Rozin, Lowery, Imada, \& Haidt, 1999; Shweder et al, 1997).

According to the literature, individuals are autonomous if they can make decisions freely and shape their lives according to their own values (e.g., Mele, 1995). Prior empirical work reveals two components thought to be required for autonomy: (a) freedom from external interference or constraints (e.g., Deci \& Ryan, 2000; Espinosa \& Starmans, 2020); and (b) the possession of certain types of decision-making capacities (Baumeister \& Monroe, 2014; Beauchamp \& Childress, 2013, Chapter 3; Starmans \& Friedman, 2016; see also Gray, Young $\&$ Waytz, 2012). The present studies focus on the latter: the decision-making capacities involved in autonomous consent, setting aside external constraints or interference by others.

Autonomous decision-making capacities are thought to include capacities for rational decision-making (e.g., the capacity to reason properly, to understand one's options, to appreciate the implications of a decision, and to make decisions on the basis of relevant reasons) and authentic decision-making (e.g., the capacity to guide one's decisions according to personal values and desires that are truly one's own; Baumeister \& Monroe, 2014; Moye et al., 2006; Starmans \& Friedman, 2016). These twin concepts are reflected in the measures of capacity (also known as "competence") used in psychiatry and clinical ethics to assess an individual's ability to give valid consent to medical treatment or participation in research (e.g., Appelbaum \& Roth, 1982).

Thus, the present studies investigate the following two hypotheses about the relationship between the consenter's autonomy and judgments of valid consent:

The Exercises Capacity Hypothesis: Whether the decision to consent is made in an autonomous (rational, authentic) way determines whether a consenter is judged to have given valid consent. 
The Mere Capacity Hypothesis: Whether or not a consenter possesses the capacity to make autonomous (rational, authentic) decisions determines whether they are judged to have given valid consent, irrespective of whether the decision to consent is in fact made in an autonomous (rational, authentic) way.

According to the Exercises Capacity Hypothesis, what goes on in the agent's mind when they are making their decision is crucial: it matters that they in fact make their decision in an autonomous way - not merely that they possess the capacity to do so. This hypothesis mirrors the importance of an agent's mental state for other kinds of moral reasoning (Chakroff \& Young, 2015).

If the Exercises Capacity Hypothesis is right, the relevance of autonomy to consent is naturally explained in terms of the way it allows agents to make autonomous (i.e., rational, authentic) decisions. For instance, a straightforward explanation for why people might care whether a consenter is intoxicated would be that these impairments make it likely that the person is in fact making a bad decision-perhaps they are doing something they don't understand (an irrational choice) or don't want to do (an inauthentic choice).

The Exercises Capacity hypothesis aligns with contemporary philosophical views of valid consent, according to which a decision to consent must in fact be rational (Savulescu \& Momeyer, 1995), well informed, voluntary, or reflective of appropriate values in order to be considered relevantly autonomous and valid (Beauchamp \& Childress, 2013; Pugh 2020). While philosophical and bioethical views of valid consent do not require that consenters make the objectively best choice, many philosophical and bioethical accounts state that the autonomous quality of the agent's decision-making - specifically, the extent to which it is rational or based on the consenter's own preferences and values - plays some kind of necessary role in determining whether consent is valid. More broadly, legal and institutional requirements of consent are thought to help protect this philosophical ideal of autonomous decision-making, in which individuals are free to promote their own well-being as defined by their own, personal values (see Berg et al., 2001, Chapter 2).

By contrast, the Mere Capacity Hypothesis contends that it matters little whether agents in fact decide autonomously; it matters only whether they have the capacity to do so. Thus, this hypothesis has the somewhat surprising implication that being incapacitated undermines consent, but not because of how this state in fact affects the agent's decision-making process; if a sober person made the exact same choice in an equally irrational or impulsive way, their decision would constitute valid consent. If the Mere Capacity Hypothesis is right, then, autonomy matters for valid consent even when the decision to consent is not an expression of the agent's autonomy; instead, it matters only that it was the decision of an autonomous agent.

\subsection{The present research}

The present studies investigate the relationship between attributions of valid consent and the autonomy of the consenter. Studies 1 and 2 investigate whether the folk concept of valid consent requires that the consenter possesses autonomous capacities, and whether it additionally requires that the consenter's choice be the product of autonomous decisionmaking. Study 3 investigates the effect of autonomous decision-making capacities on hypothesized downstream consequences of consent, including moral judgments and the allocation of rights to third parties. 
Open science. Reports of all measures, manipulations, and exclusions, as well as all data, analysis code, and experimental materials are available for download at https://osf.io/z5cdh.

\section{Study 1}

Study 1 was designed to assess whether the mere possession of autonomous decisionmaking capacities - or the exercise of those capacities - matters for the folk concept of valid concept.

\subsection{Methods}

Sample size, predictions and analyses were pre-registered (https://aspredicted.org/blind.php? $\mathrm{x}=\mathrm{Zv} 7 \mathrm{~mm} 4$ ), and our analyses adhere closely to our preregistered plans.

\subsubsection{Participants}

In line with our pre-registration, we recruited 450 participants on Amazon Mechanical Turk. After excluding participants who answered at least one of the binary-choice attention checks incorrectly, we were left with a sample of 364 participants (52.6\% male, $47.4 \%$ female; median age 36 years). ${ }^{1}$

\subsubsection{Design}

Participants were randomly assigned to read one of nine vignettes in a 3 (autonomy: Exercises Capacity; Mere Capacity; Lacks Capacity) by 3 (domain: medical consent; sexual consent; consent to police entry) between-subjects design.

\subsubsection{Procedure and materials}

The vignettes begin by explaining that an agent is facing a decision about whether to consent to something: an elective surgery (medical consent condition), sex after a date (sexual consent condition), or consenting to police entering and searching the person's home (police entry condition). The vignettes were adapted from materials used by Sommers, 2020. The full materials are available in Appendix B; here we illustrate the three conditions using the vignette from the medical domain (see Table 1). In the Exercises Capacity condition, the agent both possesses and exercises the capacity to make autonomous decisions and says "yes" based on their personal values and thinking things through rationally; in the Mere Capacity condition, the agent possesses the capacity to do this but does not exercise it, and fails to think things through rationally or base their decision on their personal values; and in the Lacks Capacity condition, the agent does not possess these autonomous decision-making capacities at all.

\begin{tabular}{l}
\hline Medical Consent Vignette \\
\hline Exercises Capacity Mere Capacity Lacks Capacity \\
Marvin has been in physical therapy for ankle pain. One day his doctor asks him whether \\
he wishes to undergo elective surgery to repair the tendon. The doctor explains that surgery \\
\hline
\end{tabular}

${ }^{1}$ Consistent with our pre-registration, we present all results with and without exclusions in Appendix A, where we also note where these exclusions made a substantial difference to results. We follow this procedure for all studies. 
would carry some risks, as all surgeries do, but if all goes well it could potentially completely cure his ankle pain.

Marvin is an intelligent, able adult. He is perfectly capable of weighing up pros and cons; thinking through the choice he faces; and making decisions based on what is best for him, which options align with his personal values, and what he really wants.

And he does so in this instance. After thinking things through very carefully — and with careful regard for the pros and cons, and whether it aligns with his personal values and what he really wantsMarvin says 'yes' to the surgery.

Marvin is an intelligent, able adult. He is perfectly capable of weighing up pros and cons; thinking through the choice he faces; and making decisions based on what is best for him, which options align with his personal values, and what he really wants.

But he doesn't do so in this instance. Without thinking things through even a little bit-and with absolutely no regard for the pros and cons, or whether it aligns with his personal values and what he really wantsMarvin says 'yes' to the surgery.
Marvin is not able and
intelligent like most adults. $\mathrm{He}$ is completely incapable of weighing up pros and cons; thinking through the choice he faces; and making decisions based on what is best for him, which options align with his personal values, and what he really wants.

So he doesn't do so in this instance. Without thinking things through even a little bit-and with absolutely no regard for the pros and cons, or whether it aligns with his personal values and what he really wantsMarvin says 'yes' to the surgery.

Table 1. Study 1 vignette used in the medical consent condition, varied by autonomy condition. Boldface type is used here for emphasis; it was not used in the stimuli presented to participants.

After reading the vignette, participants rated their agreement with a series of statements, presented in a random order, on seven-point Likert scales that ranged from strongly disagree to strongly agree.

Because "valid consent" is a technical term that may not reflect ordinary reasoning, we used three measures to assess judgments of valid consent, as follows (adapted according to vignette):

Consent 1: The doctor had Marvin's permission to proceed with the surgery.

Consent 2: If the doctor proceeds with the surgery now, he'll be acting without Marvin's consent. $^{2}$ (reverse-scored)

Consent 3: Marvin's 'yes' didn't count as consent. (reverse-scored)

According to the Mere Capacity Hypothesis, lacking capacity will be perceived as undermining valid consent, whereas failing to exercise capacity will not. Thus, the Lacks Capacity agent will be rated as lower in consent than the Exercises Capacity agent, while the Mere Capacity agent will not. By contrast, according to the Exercises Capacity Hypothesis, failing to exercise capacity will be perceived as undermining consent. Thus, both the Mere

\footnotetext{
${ }^{2}$ A typo was discovered in the measure for Consent 2 for participants in the Police Entry condition. Although the character in the vignette is called "Johnny", this measure read, "If the police officers enter and search Frank's home now, they will be acting without Johnny's consent”. However, this error did not appear to affect the results, which did not change substantially when Consent 2 was included in the overall consent composite.
} 
Capacity and the Lacks Capacity agent will be rated as lower in consent than the Exercises Capacity agent.

We also measured participants' judgments of the extent to which the agent was making the right choice by saying "yes":

Right Choice: Having surgery was probably the right choice for Marvin.

To ensure that our manipulations had the intended effect, we included four measures to check whether participants thought the agent had the general capacity to make decisions rationally and authentically (phrased as "the ability to be true to himself when making decisions"), as well as whether they thought the agent had done so in this particular instance (e.g. "Marvin made this particular decision rationally"; "When Marvin said 'yes' to having surgery, he was not being true to himself").

Following these manipulation checks, participants answered four binary-choice attention checks (e.g., "At the time the doctor suggested surgery, Marvin was capable/incapable of thinking through his choices and deciding based on the pros and cons")." We pre-registered that we would exclude participants who failed one or more of these attention checks. Finally, participants completed an exploratory measure that asked them to describe the reasoning behind their consent judgments, and a demographic survey in which they reported, in fixed order, their political views, bilingual status, age, gender, education, income, and race.

\subsection{Results}

\subsubsection{Manipulation checks}

As intended, the Autonomy manipulation was perceived as affecting capacities for rational and authentic decision-making (see Appendix A for full details). The agents in both the Exercises Capacity and Mere Capacity conditions were judged to possess capacities for rational and authentic decision-making, but the agent in Lacks Capacity was not. When it came to judgments of whether the agent made this particular decision rationally and authentically, by contrast, the agent in Mere Capacity garnered significantly lower ratings than did the agent in Exercises Capacity.

\subsubsection{Judgments of Valid Consent and Right Choice}

The three consent items created a reliable scale $(\alpha=.74)$; thus, they were averaged together to create a composite measure of consent. We analyzed this composite using the lme 4 and lmerTest packages in R (Bates, Maechler, Bolker, \& Walker et al. 2014; Kuznetsova, Brockhoff, \& Christensen, 2017). Data were fit to a linear mixed model with autonomy condition included as a fixed factor and domain included as a random factor (random intercepts only) in all models. Significance of fixed effects was assessed via $t$-tests using Satterthwaite's method.

As predicted, participants' judgments conformed to the Mere Capacity hypothesis: lacking capacity had a large undermining effect on judgments of valid consent, whereas mere failure to exercise capacity did not. Compared to the Exercises Capacity baseline $(M=5.98, S D=$ 1.08), the Lacks Capacity condition yielded significantly lower agreement that the agent gave valid consent $(M=4.78, S D=1.41), b=-1.21, S E=0.14, t=-8.81, p<.001,95 \%$ CI [-1.48, 
-0.94]. The Mere Capacity condition, by contrast, failed to yield lower agreement that the agent gave valid consent. In fact, participants gave higher ratings of valid consent in the Mere Capacity condition $(M=6.38, S D=0.84)$ than in the Exercises Capacity condition, $b=0.36$, $S E=0.15, t=2.35, p=.019$, CI $[0.06,0.65]$. Judgments of consent were significantly higher in the Mere Capacity condition than in the Lacks Capacity condition, $b=-1.56, S E=0.16, t=$ $-10.05, p<.00195 \%$ CI $[-1.87,1.26]$. See Figure 1 . An exploratory analysis treating domain as a fixed effect in a two-way ANOVA revealed no interaction between domain and autonomy condition, $F(4,355)=0.83, p=.51 .^{3}$ There was, however, a main effect of domain, $F(2,355)$ $=9.99, p<.001$ : participants gave overall lower ratings of consent in the police entry vignette.

\section{Judgments of Consent and Right Choice}
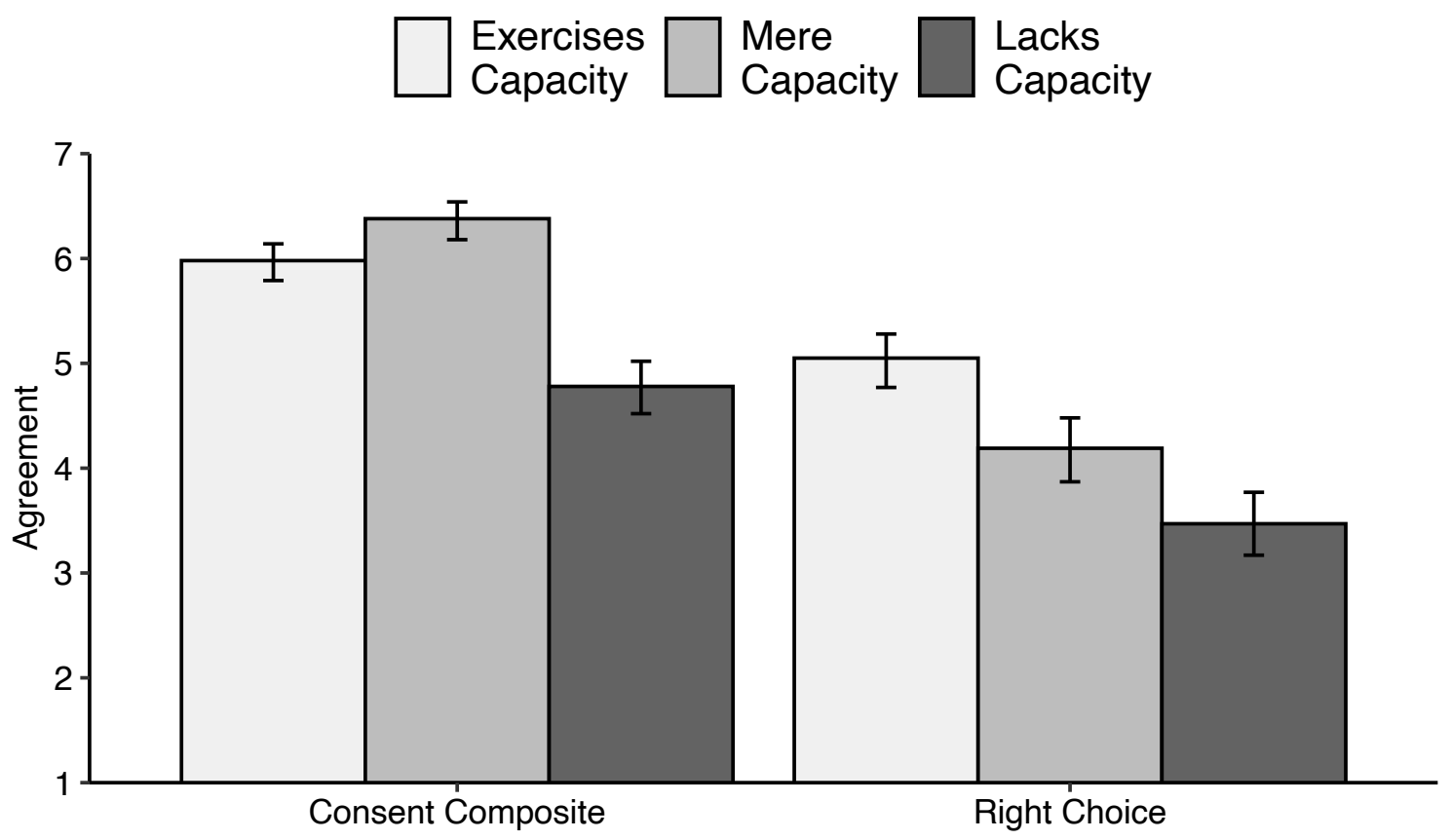

Figure 1. Respondents $(n=364)$ judged an agent who possesses autonomous decision-making capacities but fails to exercise them to give no less valid consent than an agent who both possesses and exercises such capacities. An agent who lacks autonomous decision-making capacities was viewed as giving less valid consent. This pattern was observed despite participants believing that saying 'yes' was more likely to be the right choice for the fully autonomous agent compared to the Mere Capacity agent, who in turn was more likely to have made the right choice compared to the Lacks Capacity agent. Error bars represent bootstrapped $95 \%$ confidence intervals.

Judgments of Right Choice yielded a different pattern to judgments of valid consent (Fig. 1). We predicted that assessments of whether having surgery (or having sex, allowing the police to enter) was the right choice for the agent would be affected by both the possession and the exercise of autonomous capacities. As predicted, participants exhibited lower agreement that the Mere Capacity agent $(M=4.19, S D=1.50)$ made the right choice compared to the Exercises

\footnotetext{
${ }^{3}$ In line with this, exploratory pairwise comparisons indicated that within each domain, the Lacks Capacity condition led to significantly lower ratings of valid consent.
} 
Capacity agent $(M=5.05, S D=1.57), b=-1.01, S E=0.19, t=-5.43, p<.001$, CI [-1.38, $0.65]$. Judgments were even lower among the Lacks Capacity condition $(M=3.47, S D=1.73)$ compared to the Mere Capacity condition, $b=-0.58, S E=0.19, t=-3.05, p=.002$, CI [-0.96, $-0.21]^{4}$

\section{Consent Judgments by Domain}
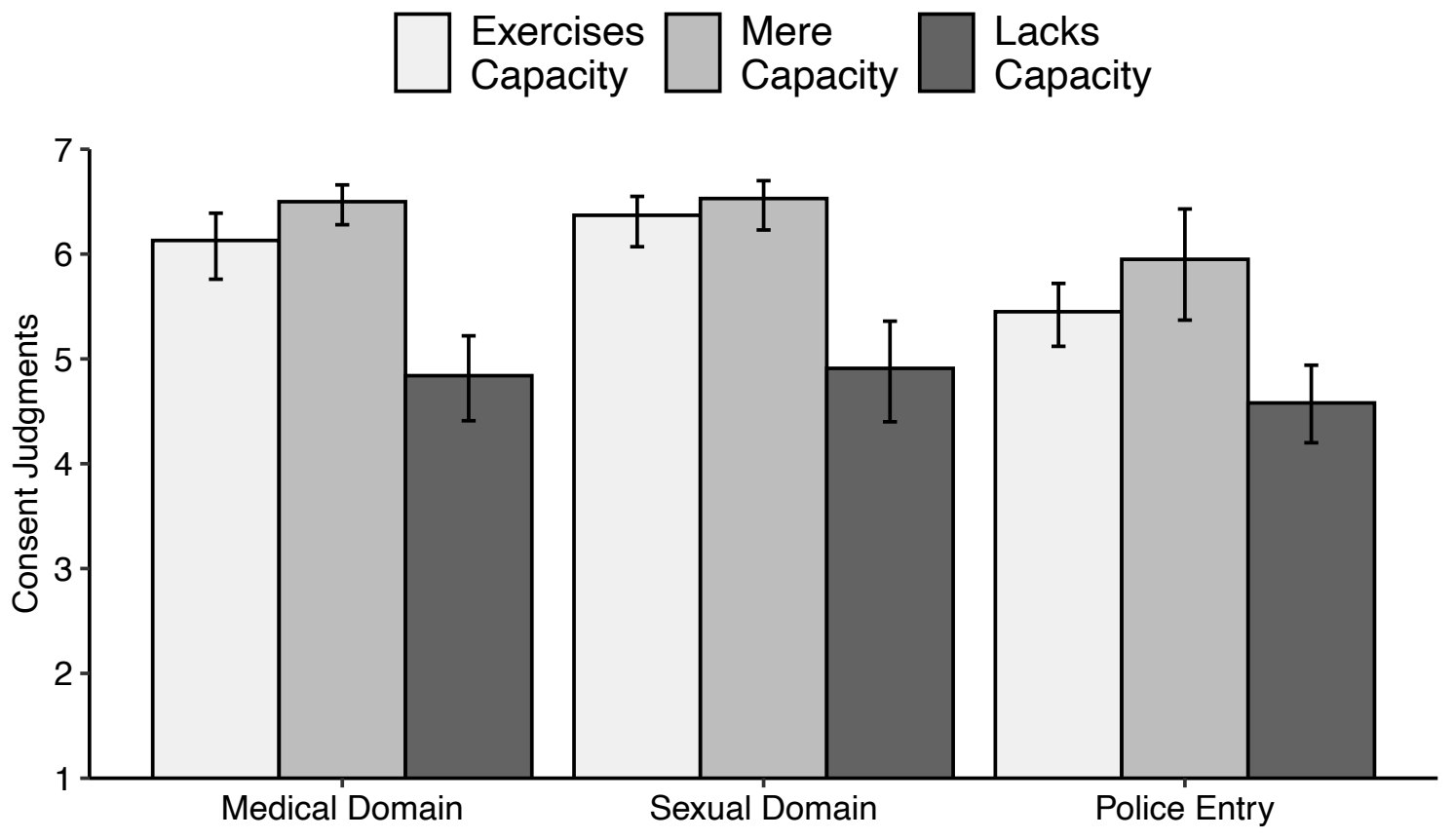

Figure 2. Across three domains, participants $(n=364)$ judged an agent who possesses autonomous decision-making capacities but fails to exercise them as validly consenting just as much as an agent who both possesses and exercises such capacities, while an agent who lacks autonomous decision-making capacity was viewed as giving less valid consent. Error bars represent bootstrapped $95 \%$ confidence intervals.

\subsection{Discussion}

The results of Study 1 suggest that autonomy plays an important role in the folk concept of valid consent: when agents lack the capacity to make autonomous decisions, as in the Lacks Capacity condition, judgments of the validity of consent are reduced. Notably, this relationship between autonomy and consent was consistent across different domains, including medical consent, sexual consent, and consent to police entering the home, suggesting that a domaingeneral concept of valid consent may be operative in reasoning about consent across these very

\footnotetext{
${ }^{4}$ An ANOVA revealed no significant interaction between condition and domain on judgments of whether the agent made the right choice, $F(4,355)=1.76, p=.14$. There was a main effect of scenario, $F(2,355)=62.49, p$ $<.001$ : participants more strongly believed that the agent in the medical scenario $(M=5.36, S D=1.12, n=128)$ made the right choice as compared to the agents in the policing $(M=3.56, S D=2.03, n=112)$ or the sexual consent $(M=3.82, S D=1.44, n=124)$ scenarios.
} 
different contexts. ${ }^{5}$ Further, the results suggest people use a concept of valid consent that goes beyond the mere question of whether the agent said "yes" or "no", since all our conditions involved agents saying "yes".

However, folk judgments were not consistent with the Exercises Capacity view of valid consent, according to which the making of a decision in an autonomous manner is crucial for determining the validity of consent. Participants did not rate the consent of the Mere Capacity agent as any less valid compared to the Exercises Capacity agent, even though the Mere Capacity agent was described as saying "yes" without any regard whatsoever for the pros or cons or their own values.

This finding was observed despite the fact that participants recognized that failing to exercise autonomous decision-making has a strong impact on quality of choice, as indicated by our manipulation checks and our "Right Choice" measure: participants tended to disagree that the Mere Capacity agents were deciding rationally, and tended to disagree or neither agree nor disagree that they were being true to themselves and making the right choice. By contrast, participants overwhelmingly agreed that the Exercises Capacity agents were deciding rationally and being true to themselves, and tended to agree that they were making the right choice. Nevertheless, this assessment did not lead participants to judge that their consent was more valid. It therefore seems that while participants appear to view autonomous decisionmaking as valuable, they do not view it as required for valid consent.

Thus, participants' judgments accorded with the Mere Capacity view of valid consent, according to which it is only required that the consenter possesses capacities for autonomous decision-making, even if they do not exercise them.

Surprisingly, we found that judgments of the validity of consent were slightly higher for the Mere Capacity agent. Because the vignette in this condition emphasized that the agent in question failed to make his decision in a rational manner that was sensitive to his own values, even though they had the capacity to do so, participants may have felt that the vignette was implicitly suggesting that failing to make the decision autonomously can undermine consent. We suspect that participants may then have given even stronger ratings of valid consent (close to ceiling) to express disagreement with this implicit suggestion.

\section{Study 2}

Study 2 sought to determine the robustness of the finding that whether an agent possesses autonomous decision-making capacities, but not whether the agent makes a decision in an autonomous manner, is crucial for judgments of valid consent, while overcoming some limitations of Study 1.

\footnotetext{
${ }^{5}$ Exploratory analyses indicated that the Police Entry vignette yielded lower ratings of valid consent overall compared to the Sexual and Medical consent vignettes. A number of features of the vignette may have contributed to this. Firstly, the consent in the Police Entry vignette may have been perceived to be less free due to stronger power dynamics: unlike in the other vignettes, the people requesting consent in Police Entry were two police officers, and thus may have been perceived to be in a greater position of power and authority compared to the single doctor or the single sexual partner as described in the other vignettes. Second, participants may have been motivated to give lower ratings of consent because they disapprove of the kind of police search described by the vignette, irrespective of the citizen's consent.
} 
First, Study 2 investigates whether the finding is observed even if participants are given descriptions of more concrete features of irrational or inauthentic decision-making. In Study 1, participants were presented with a description of a decision-making process at a high level of abstraction. Furthermore, the vignettes offered no information about why the Mere Capacity agent failed to make the decision autonomously. It remains possible, then, that participants would take the failures to engage in autonomous decision-making to reduce the validity of consent if offered more concrete descriptions of irrationality or inauthenticity. If so, this would suggest that the folk concept coheres with the Exercises Capacity view of valid consent after all. Consequently, Study 2 was designed to test whether our findings would extend to more concrete, realistic, and varied failures of autonomy. We did this by using vignettes involving a variety of ways in which an agent might fail to make their decision autonomously: by acting impulsively, giving in to peer pressure, basing a decision on irrational beliefs, or making an uninformed choice despite the availability of crucial information.

Second, in Study 1 participants were given no explicit information about whether saying "yes" was the right outcome for the agent. Because of this, even if the Mere Capacity agent did not make the decision in a rational or authenticity-preserving way, the scenario left open the possibility that the activity in question was in fact the option that best cohered with their reasons and values. For instance, participants might judge that having corrective surgery is likely to cohere with the values of a competent agent seeing the doctor about their ankle pain. Study 2 sought to use a more stringent test of whether the folk concept of valid consent merely requires autonomous decision-making capacities or whether it additionally requires the making of autonomous decisions by using vignettes that specify that the agent in the Mere Capacity and Lacks Capacity conditions makes the wrong decision relative to their reasons and values, while the Exercises Capacity agent makes the right decision.

Finally, we also included an additional pair of manipulation checks to ensure that our autonomy conditions mirrored folk judgments about autonomy-namely the ability to shape one's life freely according to one's values. For instance, we asked participants to rate their agreement with "The way Marvin made this particular decision expressed an ability to shape his life freely according to his own values and what is right for him." This allowed us to rule out the possibility that participants think the Mere Capacity agent is deciding in a way that is equally as autonomous as the Exercises Capacity agent (e.g., because participants surmise that the Mere Capacity agent is making an autonomous decision not to exercise his capabilities, thus expressing a kind of meta-autonomous desire to make the choice in a nonautonomous way).

\subsection{Methods}

Sample size, predictions and analyses were pre-registered (https://aspredicted.org/blind.php? $\mathrm{x}=\mathrm{gs} 43 \mathrm{rp}$ ).

\subsubsection{Participants}

In line with our pre-registration, we recruited 600 participants on Amazon Mechanical Turk. After excluding participants who failed at least one of the attention checks, we were left with a sample of 384 participants $(49.6 \%$ male, $49.6 \%$ female, $0.8 \%$ other gender; median age 37 years).

\subsubsection{Design}


Participants were randomly allocated to one of twelve conditions in a 3 (Autonomy: Exercises Capacity; Mere Capacity; Lacks Capacity) by 4 (Failure Type: Impulse; Peer Pressure; Uninformed; Irrational Superstition) between-subjects design.

\subsubsection{Procedure and materials}

Each participant was presented with a vignette in which an agent, Marvin, is facing a choice about whether to undergo an elective surgery and ends up saying "yes." Before saying "yes," he faces the possibility of having his decision non-autonomously determined by impulse, peer pressure, lack of information, or irrational superstition (depending on Failure Type). Autonomy conditions determined whether he possessed the capacity to make the decision according to his values and reasons, and whether or not he in fact did so.

As in Study 1, the Exercises Capacity agent is described as having the capacity to make the decision in an autonomous, rational manner (e.g., able to make decisions for himself and override impulses when they are inappropriate), as in fact doing so (e.g., resisting an initial, impulsive reaction to say "no", and instead thinking things through in a rational and authentic way), and as a result saying "yes." This is described as the right choice for him.

The Mere Capacity agent is described as having these very same capacities, but as not exercising them (e.g., giving in to an initial impulsive reaction to say "yes" without thinking things through in a rational or authentic way) and as a result saying "yes" even though that is not the right choice for him. The Lacks Capacity agent lacks these capacities altogether (e.g., he is not able to make decisions for himself and resist inappropriate impulses) and thus says "yes" even though it is not the right choice for him. See Table 2 for an illustration of the vignettes used in the Impulse condition; full text for all conditions is available in Appendix B.

\begin{tabular}{|c|c|c|}
\hline \multicolumn{3}{|l|}{ Intro paragraph (all conditions): } \\
\hline \multicolumn{3}{|c|}{$\begin{array}{l}\text { Marvin has been in physical therapy for ankle pain. One day his doctor asks him whether he } \\
\text { wishes to undergo elective surgery to repair the tendon. The doctor explains that the surgery } \\
\text { carries some risks, as all surgeries do, but if all goes well it could potentially completely cure } \\
\text { his ankle pain. }\end{array}$} \\
\hline Exercises Capacity: & Mere Capacity: & Lacks Capacity: \\
\hline $\begin{array}{l}\text { Marvin feels an initial } \\
\text { impulse to simply say 'no' to } \\
\text { surgery. }\end{array}$ & $\begin{array}{l}\text { Marvin feels an initial } \\
\text { impulse to simply say 'yes' } \\
\text { surgery. }\end{array}$ & $\begin{array}{l}\text { Marvin feels an initial } \\
\text { impulse to simply say 'yes' } \\
\text { surgery. }\end{array}$ \\
\hline $\begin{array}{l}\text { Marvin is an intelligent, able } \\
\text { adult, fully capable of } \\
\text { making decisions for himself } \\
\text { and controlling impulses } \\
\text { when they are inappropriate. }\end{array}$ & $\begin{array}{l}\text { Marvin is an intelligent, able } \\
\text { adult, fully capable of } \\
\text { making decisions for himself } \\
\text { and controlling impulses } \\
\text { when they are inappropriate. }\end{array}$ & $\begin{array}{l}\text { Marvin is not able and } \\
\text { intelligent like most adults } \\
\text { who are fully capable of } \\
\text { making decisions for } \\
\text { themselves: he is completely } \\
\text { incapable of controlling } \\
\text { impulses, even when they are } \\
\text { inappropriate. }\end{array}$ \\
\hline $\begin{array}{l}\text { And he does so in this } \\
\text { instance. Although he feels }\end{array}$ & $\begin{array}{l}\text { But he does not do so in this } \\
\text { instance. Acting on an }\end{array}$ & $\begin{array}{l}\text { So he does not do so in this } \\
\text { instance. Acting on an }\end{array}$ \\
\hline
\end{tabular}


an initial impulse to avoid surgery, he thinks things through carefully, and makes his decision with careful regard for the pros and cons, and whether surgery aligns with his personal values and what he really wants. Because of this, Marvin says 'yes' to the surgery.

If he had not resisted his initial impulse and made a decision based on thinking things through properly, Marvin would have said 'no', despite surgery being the right choice for him.

Table 2. Vignette used in the Impulse Failure Type condition, with variations according to Autonomy condition. Boldface type is used here for emphasis; it was not used in the stimuli presented to participants. initial impulse to have the surgery, he doesn't think things through even a little bit, and pays absolutely no attention to the pros and cons, or whether surgery aligns with his personal values and what he really wants. He simply says 'yes' to the surgery on an impulse.

If he had resisted his initial impulse and made a decision based on thinking things through properly, Marvin would have said 'no', as it is not the right choice for him. initial impulse to have the surgery, he doesn't think things through even a little bit, and pays absolutely no attention to the pros and cons, or whether surgery aligns with his personal values and what he really wants. He simply says 'yes' to the surgery on an impulse.

If he had resisted his initial impulse and made a decision based on thinking things through properly, Marvin would have said 'no', as it is not the right choice for him.

As in Study 1, participants rated their agreement with a number of statements presented in a random order on a seven-point Likert scale. We used the same three measures to assess judgments of valid consent (e.g., "Marvin's 'yes' didn't count as consent").

In addition to the manipulation check measures from Study 1, we added two manipulation check questions eliciting judgments of autonomy:

Capacity for autonomy: Marvin has the ability to shape his own life freely according to his own values and what is right for him.

Decided autonomously: The way Marvin made this particular decision expressed an ability to shape his life freely according to his own values and what is right for him.

Following the Likert-scale measures, we again included attention checks. Participants were asked three binary-choice questions, presented in random order, concerning (1) the agent's capacities; (2) the way they made the decision, and (3) whether they made the right choice. (In other words, in Study 2 "right choice" was included as a manipulation check rather than as a main dependent measure.) For instance, the attention checks in the Impulse condition were: "Marvin is/is not able to resist and overcome impulses."; "Marvin made this particular decision by thinking it through properly/on an impulse."; "Having surgery was/was not the right choice for Marvin."

Finally, participants completed an exploratory question explaining their answer and a demographic survey as in Study 1.

\subsection{Results}




\subsubsection{Manipulation checks and autonomy judgments}

Again, participants' conceptual judgments exhibited the predicted patterns (see Appendix A for full details). As intended, both the Exercises Capacity and Mere Capacity agent were judged to possess capacities for rational, authentic, and autonomous decision-making, but the Lacks Capacity agent was not. Also as intended, the agent in Mere Capacity was rated significantly lower on having made this particular decision rationally, authentically and autonomously compared to the Exercises Capacity agent.

\subsubsection{Judgments of Valid Consent}

Again, we created a composite measure of judgments of valid consent $(\alpha=.73)$. We fit a linear mixed model with autonomy condition included as a fixed factor and failure type included as a random factor. The model was a singular fit because of an estimate of zero variance for the intercept, suggesting that the model did not warrant a random effect of failure type (e.g., Henne et al., 2019). Hence, we simplified the model, using a linear model with no random effects.

In line with our hypotheses, participants rated consent as higher in the Exercises Capacity condition $(M=6.15, S D=1.23)$ than in the Lacks Capacity condition $(M=5.21, S D$ $=1.28), b=-0.94, S E=0.15, t=-6.42, p<.001$, CI $[-1.22,-0.65]$, but no higher than in the Mere Capacity condition $(M=5.93, S D=1.17), b=-0.22, S E=0.16, t=-1.38, p=.17$, CI [0.54, 0.09]. Judgments of consent differed significantly between the Mere Capacity condition and the Lacks Capacity condition, $b=-0.71, S E=.17, t=-4.30, p<.001$ CI [-1.04, -0.39$]$. See Figure 3. From a Bayesian perspective, these results provided support for the absence of an effect of Exercising Capacity vs. Mere Capacity on consent judgments, though the evidence for this null result is "weak" or "anecdotal," falling short of "positive" or "substantial" $\left(\mathrm{BF}_{10}\right.$ $=0.36){ }^{6}$

In line with our pre-registration, we confirmed, via a two-way ANOVA in which failure type was treated as a fixed effect, that the interaction between autonomy condition and failure type was not significant, $F(6,372)=.58, p=.75 .{ }^{7}$ Despite this, we conducted exploratory post hoc pairwise comparisons within the Uninformed failure type, using the Holm correction to adjust $p$, to explore the possibility that this vignette yielded a different effect of condition (see Figure 3 ). These post hoc tests revealed that consent judgments did not differ significantly between Exercises Capacity and Mere Capacity conditions in the Uninformed vignette $(p=$ $.084)$, but they did differ between the Exercises Capacity and Lacks capacity conditions $(p<$ .001). Consent judgments did not differ between the Mere Capacity and Lacks Capacity conditions $(p=.25)$.

\footnotetext{
${ }^{6}$ This Bayesian $t$-test was not pre-registered, but was helpfully suggested by a reviewer.

${ }^{7}$ This finding further justified collapsing across Failure Type. The ANOVA revealed a main effect of autonomy condition, $F(2,372)=21.36, p<.001$. There was no main effect of Failure Type, $F(3,372)=.54, p=.66$.
} 


\section{Consent Judgments by Failure Type}
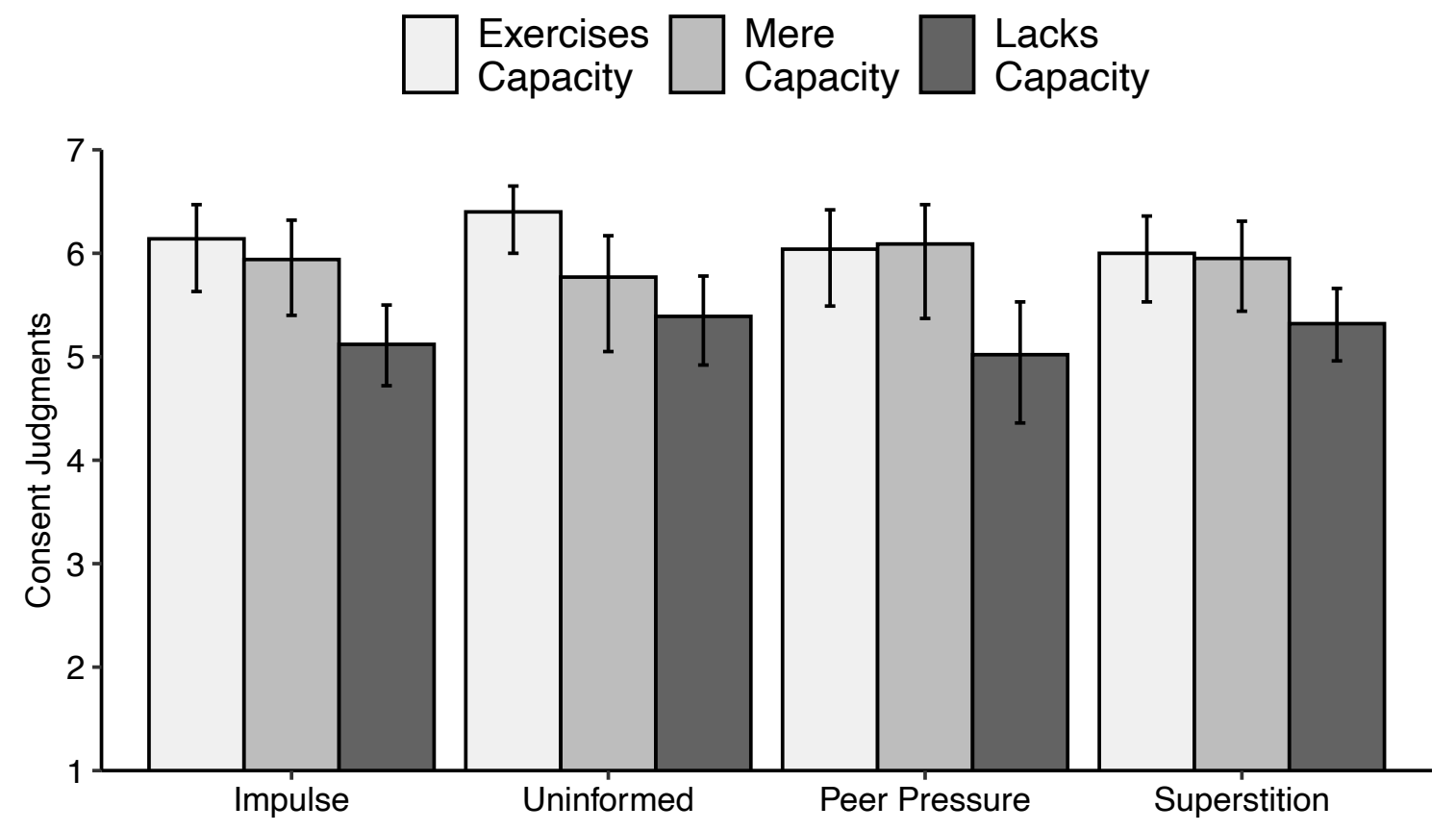

Figure 3. Results from Study 2 for mean agreement that the agent gave valid consent. Compared to an agent who possessed and exercised autonomous decision-making capacities, participants $(n=$ 381) were not less likely to judge that an agent gave valid consent when they possessed autonomous decision-making capacities but failed to exercise them in some way (through impulse, being uninformed, peer pressure, or irrational superstition). Participants were significantly less inclined to agree that an agent who lacked an autonomous decision-making capacity gave valid consent. Error bars represent bootstrapped $95 \%$ confidence intervals.

\subsection{Discussion}

Study 2 replicated and extended our main findings from Study 1. Once again, judgments of valid consent were related to the possession of autonomous capacities, but not to the exercise of those capacities. As in Study 1, it didn't matter whether the consenter actually made the decision for himself in an autonomous way: participants regarded the consent of an agent with autonomous decision-making capacities to be equally valid even if he did not make this particular decision autonomously. This was so even though we explicitly specified that the Mere Capacity agent would have said "no" had he made the decision properly, because it wasn't the right choice for him, whereas the Exercises Capacity agent would have said "yes."

We found this pattern for a number of different "Failure Types" that invoked particular, concrete capacities involved in autonomous decision-making. For instance, judgments of consent were reduced when the agent lacked the general ability to control impulses, to resist peer pressure, to get relevant information, or to distinguish reasonable from unreasonable ways of making decisions. Judgments of the validity of the agent's consent were not lower when the agent retained those capacities but said "yes" on impulse, because of peer pressure to say "yes," because of a failure to inform themselves, or because of an irrational and unreasonable superstition. 
These findings thus provide stronger evidence that whether an agent makes an autonomous decision is not important for judgments that consent was valid, even though having the capacity to make an autonomous decision does matter.

While this main finding was consistent across different Failure Types, the Uninformed category appeared to creep towards subtly different results. While post hoc analyses indicated that only the Lacks Capacity condition yielded significantly lower judgments of valid consent compared to Exercises capacity, in line with our main findings, the Uninformed Mere Capacity agent appeared closer to the Lacks Capacity agent than the Exercises Capacity agent.

One possible explanation for the appearance of a different trend for the Uninformed category that the vignette described a case of consent to a medical procedure. Unlike other consent contexts, medicine is associated with explicit institutional and cultural norms of the importance of so-called "informed consent." Awareness of this norm could have reduced ratings in the Mere Capacity condition, either because participants agreed with this domainspecific norm, or because awareness of this norm affected participants' judgments of consent.

Another possibility, of course, is that the apparent deviation from the main pattern in this condition is simply noise due to random error. Future research could confirm whether attempting to inform oneself is important for judgments of valid consent, preferably using a larger array of vignettes including non-medical contexts.

\section{Study 3}

Studies 1 and 2 establish that judgments of valid consent vary according to autonomy. But in what respect does it matter whether a "yes" is judged to be valid or invalid? Are these judgments superficial, merely reflecting how words like "consent" are used, without playing an important role in moral reasoning? We designed Study 3 to investigate whether participants intuitively embrace a normative concept of valid consent akin to that employed in philosophical and legal spheres by examining whether their judgments of valid consent carry important downstream consequences for moral reasoning.

How might consent affect moral reasoning? One obvious answer is that it's more morally wrong to perform an action (e.g., take something that belongs to someone else) if it was not validly consented to. For example, recent work by Rodríguez-Arias and colleagues (2020) on the topic of physician-assisted suicide suggests that consent has important implications for moral judgments. Specifically, their studies showed that consent is responsible for the morally motivated causal distinction between 'killing' and 'letting die': if a patient consents to ending their life, then the cause of death is judged to be the patient's illness, but if the patient does not consent, the doctor is seen as 'killing' the patient. It appears that here the giving of consent affects whether the doctor's action is construed as permissible assistance or as something morally wrong.

However, according to the philosophical and legal concept, the effect of valid autonomous consent should be even more far-reaching than its effect on judgments of the moral permissibility of performing the consented-to act: consent should additionally determine various parties' rights and obligations. 
As described earlier, the presence or absence of valid consent is thought to be crucial even if the consented-to act is morally wrong. Adulterous sex might be morally wrong regardless of consent, for instance, but the presence or absence of consent is thought to determine both the severity and criminality of the wrong. Crucially, the presence or absence of consent carries consequences for rights and obligations, such as the right or duty of third parties to forcibly intervene in the case of rape but not adultery; of police to arrest the rapist; the right of the sexual partner to seek redress and justice in the case of rape; and so on. Consent similarly functions to alter rights and obligations in other domains: consent is thought to determine whether or not a signer is bound by the terms of a contract. in the case of ownership, consent determines if the taking of an item constitutes a sale, and thus the successful transfer of ownership rights to a new owner (rather than, e.g., a theft).

In Study 3, we chose to study whether the effect of autonomy on judgments of valid consent carries downstream consequences for judgments of ownership transfer. As discussed in the introduction, prior research suggests that the presence or absence of consent plays a role in the ascription of ownership rights. Prior research suggests that adults and children reason about violations of ownership rights in a very similar way to how they reason about violations of bodily rights (Van de Vondervoort \& Friedman, 2015), which supports our hypothesis that the same concept of valid consent should extend to this domain. Studying ownership also allowed us to extend the findings from Study 1 and Study 2 to a new context.

Study 3 employed a vignette in which the owner of an item gives consent to a second party (the seller) to sell that item; the item is then bought by an innocent third party (the buyer). Introducing a blameless third party provided a clean way to assess the potential downstream consequences of the validity of consent. For instance, if an owner consents to selling something only because they haven't thought it through properly, and the seller knows this, participants might reasonably judge that the seller is doing something morally wrong, since they are knowingly doing something that's bad for the consenter/original owner. Nevertheless, based on Studies 1 and 2, we predicted that participants would judge such a transaction to be consensual. Thus, assessing the allocation of rights to an innocent third party (the buyer) allowed us to differentiate the effect of autonomous consent on the morality of the consentedto action, on the one hand, and its impact on rights, on the other.

We predicted that whether participants judge that ownership rights have transferred to the buyer of an item would depend on whether they judged that the original owner gave valid consent to the sale, which itself would depend on the possession of autonomous decisionmaking capacities. Thus, we hypothesized that if the consenter (the original owner) has autonomous decision-making capacities, then consent will be judged to be valid, and the buyer will be judged to have been conferred ownership rights. By contrast, if the consenter lacks autonomous decision-making capacities, then participants will judge consent to have been invalid; in turn, we expect them to judge that the consenter retains ownership rights and that the buyer has failed to gain ownership rights. Importantly, we expected that whether the consenter exercises autonomous decision-making capacities would not have an impact on valid consent or the transfer of ownership rights.

\subsection{Methods}

Sample size, predictions and analyses were pre-registered (https://aspredicted.org/blind.php? $\mathrm{x}=2 \mathrm{fv} 78 \mathrm{~s}$ ). 


\subsubsection{Participants}

In line with our pre-registration, we set out to recruit 300 participants on Amazon Mechanical Turk; 303 were recruited due to random M-Turk software error. After excluding participants who failed at least one of the attention checks $(\mathrm{N}=143)$ and additional participants who wrote gibberish $(\mathrm{N}=7)$, we were left with a sample of 153 participants $(59.5 \%$ male, $40.5 \%$ female; median age 34 years). Responses classified as gibberish included nonsense, responses that were identical to those of other participants, copy-and-pasted material from the experiment, and irrelevant copy-and-pasted material from the internet.

\subsubsection{Design}

Participants were randomly allocated to one of three Autonomy conditions in a fully between-subjects design: Exercises Capacity; Mere Capacity; Lacks Capacity.

\subsubsection{Procedure and materials}

All participants were presented with a vignette in which an agent, Jessica, is in hospital recovering from a procedure. The full text is available in Appendix B. Sam comes to visit Jessica and asks for consent to sell her diamond bracelet - a bracelet which is very precious to her but which he thinks could make them a lot of money.

In all conditions, Jessica says "yes", but her autonomy differs according to condition. In the Exercises Capacity and Mere Capacity conditions, Jessica is not on heavy medication. She is described as being "perfectly capable of weighing up pros and cons, thinking through choices she faces, and making decisions based on what is best for her, which options align with her personal values, and what she really wants," and although she is on medication, "it's only ibuprofen and some antibiotics. In fact, she feels calm and lucid, and nothing is interfering in any way with her ability to think or make decisions."

In the Exercises Capacity condition, she goes on to use these capacities to make her decision to consent in an autonomous way: "using her ability to make decisions according to her own values and what is best for her, Jessica says 'yes' after thinking things through very carefully, with careful regard for the pros and cons and whether it's what she really wants." By contrast, in the Mere Capacity condition, "despite her ability to make decisions according to her own values and what is best for her, Jessica just says 'yes' to the sale without thinking things through even a little bit, and with absolutely no regard for the pros and cons or whether it's what she really wants."

Finally, in the Lacks Capacity condition, Jessica is on heavy medication that undermines her decision-making capacities: "the medication she is on is incredibly powerful and is severely interfering with her ability to think and make decisions. Indeed, in her current state she is completely incapable of weighing up pros and cons, thinking through choices she faces, or making decisions based on what is best for her, which options align with her personal values, or what she really wants." Consequently, she does not make her decision in her autonomous way: "so Jessica says 'yes' to the sale without thinking things through even a little bit, and with absolutely no regard for the pros and cons, or whether it's what she really wants." 
For all participants, Sam is described as being only motivated by making money, and not caring about which decision will make Jessica happy; in fact, he proceeds even though he suspects that Jessica will regret her decision.

The vignette then goes on to describe the completion of the sale by Sam to a blameless third party, Melanie, who sees the bracelet advertised as for sale online, pays for it, and receives the bracelet in the mail two days later.

After reading the vignette, participants rated their agreement with a series of statements, presented in a random order, on seven-point Likert scales. The vignette remained visible to participants for their reference.

We measured judgments of valid consent, morality, and ownership rights using agreement with a seven-point Likert scale. The three consent measures closely matched those used in Studies 1 and 2 (e.g., "Jessica's 'yes' didn't count as consent"). Moral judgments of the consented-to action were measured as follows:

Morality: Under these circumstances, it was morally wrong for Sam to proceed with selling the bracelet. (reverse-scored)

We also used five new "ownership transfer" measures using a seven-point Likert scale from "strongly disagree" to "strongly agree." These were designed to assess judgments of the rights and obligations of the buyer, Melanie.

Ownership Transfer 1: The bracelet does not truly belong to Melanie. (reversescored)

Ownership Transfer 2: Even if Melanie was told about the bracelet's true history, it would be morally acceptable for her to keep the bracelet if that's what she wanted to do.

Ownership Transfer 3: If Melanie was told about the bracelet's true history, it wouldn't just be nice of her to give the bracelet back to Jessica: it would be her moral duty to give it back. (reverse-scored)

Ownership Transfer 4: Melanie should be forced to return the bracelet. (reversescored)

Ownership Transfer 5: A good law would require the bracelet to be returned to Jessica under these circumstances. (reverse-scored)

At the start of Ownership Transfer 2-5 measures, the question instructions clarified, "Assume that Melanie could return the bracelet to Jessica and get her money back. Do you agree with the following statement?" This was to make sure that participants' answers reflected judgments about whether ownership rights to the bracelet transferred to Melanie, and not concerns about Melanie's money. For this reason, Ownership Transfer measures 2-5 were presented one after the other (in a random order) to aid participant comprehension, instead of fully randomizing the order of all measures. 
follows:

In addition, we included one binary multiple-choice measure of ownership judgments as

Ownership, binary: Who is the rightful owner of the bracelet? [Options: Jessica/Melanie]

We additionally included manipulation checks as in Study 1.

Participants then completed two multiple-choice comprehension checks ("Which is correct? Jessica's medication interfered with her ability to think/Jessica's medication DID NOT interfere with her ability to think" and "Which is correct? Jessica said 'yes' WITH regard for whether she really wanted to sell the bracelet / Jessica said 'yes' WITHOUT regard for whether she really wanted to sell the bracelet").

Finally, participants answered an exploratory open-ended question explaining their reasoning, provided demographic information, and were debriefed.

\subsection{Results}

\subsubsection{Manipulation checks}

Our manipulations checks confirmed that the autonomy conditions successfully manipulated participants' judgments of Jessica's autonomy in largely the desired way, with minor exceptions.

Judgments of whether Jessica made the decision to consent rationally and authentically showed the predicted pattern. While agreement that she made this decision rationally and authentically was high in the Exercises Capacity condition, participants tended to disagree that she made this decision rationally and authentically in the Mere Capacity and Lacks Capacity conditions.

Judgments of whether Jessica possessed the capacity for autonomous decision-making largely, but not entirely, conformed to predicted patterns. As expected, participants tended to disagree that Jessica had the capacity to make decisions rationally $(M=2.11, S D=1.60)$ and authentically $(M=2.25, S D=1.70)$ in the Lacks Capacity condition, while participants tended to agree that she had the capacity in both the Exercises Capacity agent and the Mere Capacity conditions. However, contrary to expectations, agreement with these measures was significantly lower in the Mere Capacity condition compared to the Exercises Capacity condition. Jessica was regarded as less capable of rationality in the Mere Capacity condition $(M=4.96, S D=1.73)$ compared to the Exercises Capacity condition $(M=5.88, S D=1.12)$, $t_{\text {Welch }}(83.00)=3.08, p=.003$. Additionally, she was regarded as having lower capacity for authenticity in the Mere Capacity condition $(M=4.80, S D=1.86)$ compared to the Exercises Capacity condition $(M=5.74, S D=1.18), t_{\text {Welch }}(82.25)=2.96, p=.004$.

\subsubsection{Judgments of Valid Consent}

A composite measure of judgments of valid consent was created by averaging together Consent 1, Consent 2 (reverse-scored), and Consent 3 (reverse-scored) $(\alpha=.89)$.

A one-way ANOVA revealed a significant effect of autonomy condition on judgments of valid consent, $F(2,150)=59.82, p<.001$ (Fig. 4). Pairwise comparisons of estimated marginal 
means indicated that, as predicted, participants showed lower agreement that the agent in Lacks Capacity gave valid consent $(M=2.75, S D=1.53)$ relative to the Mere Capacity agent $(M=$ $4.80, S D=1.56), b=-2.05, S E=.28, t=-7.25, p<.001$, CI [-2.61, -1.49].

Participants also showed slightly lower agreement that the agent in the Mere Capacity condition gave valid consent compared to the Exercises Capacity condition $(M=5.84, S D=$ $1.27), b=-1.03, S E=0.31, t=-3.36, p=.001$, CI [-1.64, -0.43].

Nevertheless, mean ratings of valid consent in the Mere Capacity condition, $t(48)=3.60$, $p<.001, d=\underline{0.51}$, and the Exercises Capacity condition, $t(42)=9.46, p<.001, d=1.44$, were both significantly above midpoint. By contrast, mean rating of valid consent in the Lacks Capacity condition was significantly below midpoint $(t(60)=-6.35, p<.001, d=-\underline{0} .81){ }^{8}$

\subsubsection{Judgments of Ownership Rights}

The Likert ownership rights measures 1 and 3-5 were reverse-scored, so that for all measures, higher score indicates greater agreement that ownership rights have been successfully transferred (i.e. that the buyer, Melanie, is now the rightful owner of the bracelet, and that the previous owner, Jessica, no longer has rights to it). The five measures of ownership transfer showed very high scale reliability $(\alpha=.89)$, so a composite measure of ownership transfer was created by averaging together all five variables.

The effect of condition on judgments of ownership transfer mirrored the pattern found for judgments of valid consent, $F(2,150)=35.60, p<.001$ (Fig. 4). Pairwise comparisons of estimated marginal means indicated that participants showed lower agreement that ownership had been transferred in the Lacks Capacity condition $(M=3.18, S D=1.40)$ relative to the Mere Capacity agent $(M=4.71, S D=1.58), b=-2.35, S E=.29, t=-8.14, p<.001$, CI [-2.92, -1.78$]$. Participants also showed slightly lower agreement that ownership transferred in the Mere Capacity condition compared to the Exercises Capacity condition $(M=5.53, S D=1.36), b=$ $0.82, S E=.31, t=2.69, p=.008$, CI [-1.41, -0.22].

\footnotetext{
${ }^{8}$ We thank a reviewer for suggesting these additional analyses. These comparisons to midpoint were not preregistered.
} 


\section{Consent Judgments and Downstream Consequences}
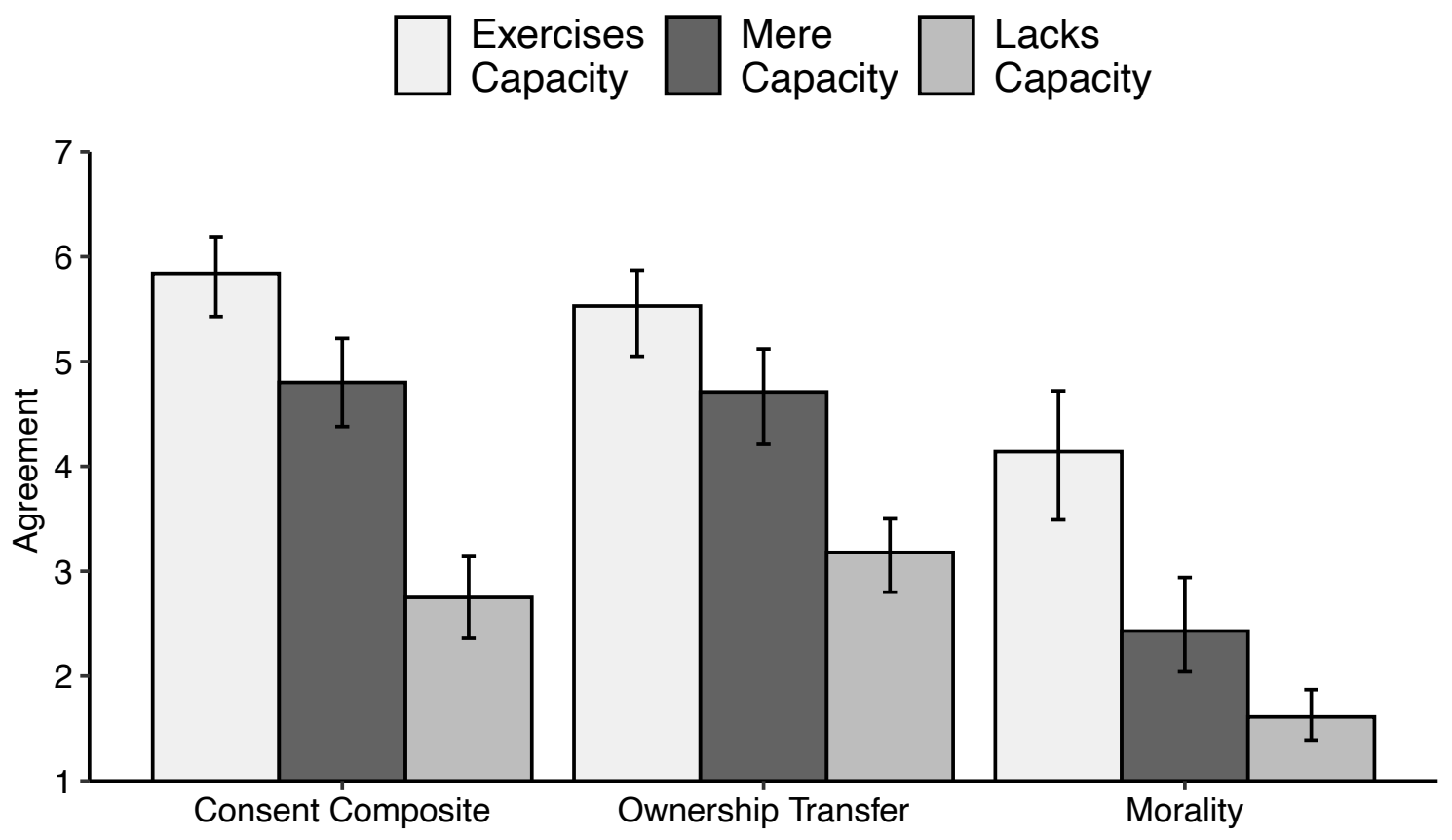

Figure 4. Results for Study 3 showing the effect of Autonomy condition on mean agreement that (i) there was valid consent, (ii) ownership rights transferred to the buyer, (iii) it was morally permissible for Sam to sell the bracelet. Error bars represent bootstrapped 95\% confidence intervals.

The binary choice measure of ownership rights showed a similar pattern. In the Exercises Capacity and Mere Capacity conditions, the majority of participants said that the bracelet now belonged to Melanie $(81.40 \%$ and $57.14 \%$ respectively), but in the Lacks Capacity condition only a minority chose Melanie as the rightful owner (21.31\%). Fisher's exact tests confirmed that in the Lacks Capacity condition, significantly fewer participants said that the bracelet now belonged to Melanie compared to the Mere Capacity condition (Odds ratio $(\mathrm{OR})=0.21, p<.001, \mathrm{CI}[0.08,0.50])$, and compared to the Exercises Capacity condition $(\mathrm{OR}=0.06, p<.001, \mathrm{CI}[0.02,0.18])$. The difference in ownership transfer judgments between Mere Capacity and Exercises Capacity was also significant (OR $=0.31, p=.014$, CI [0.10, $0.86])$.

\subsubsection{Judgments of Morality}

Moral judgments were reverse-scored so that higher scores indicate higher agreement that it was morally permissible to sell the bracelet, whereas lower scores indicate that it was not morally permissible to sell the bracelet. We observed a significant effect of Autonomy condition on moral judgments, $F(2,150)=35.27, p<.001$ (Fig. 4). Pairwise comparisons indicated that, as predicted, participants tended to disagree more that this was morally permissible in the Lacks Capacity condition, $(M=1.61, S D=.94)$ compared to the Mere Capacity condition $(M=2.43, S D=1.62), b=0.82, S E=.29, t=-2.81, p=.005$, CI [-1.40, $0.24]$ ), where participants also exhibited strong disagreement that Sam's conduct was morally permissible. The agent in Exercises Capacity $(M=4.14, S D=2.01)$ was viewed as acting more permissibly as compared to the agent in Mere Capacity, $b=-1.71, S E=0.32, t=-5.38, p<$ $.001, \mathrm{CI}[-2.34,-1.08])$. 


\subsubsection{Relationship Between Judgments of Consent and Ownership}

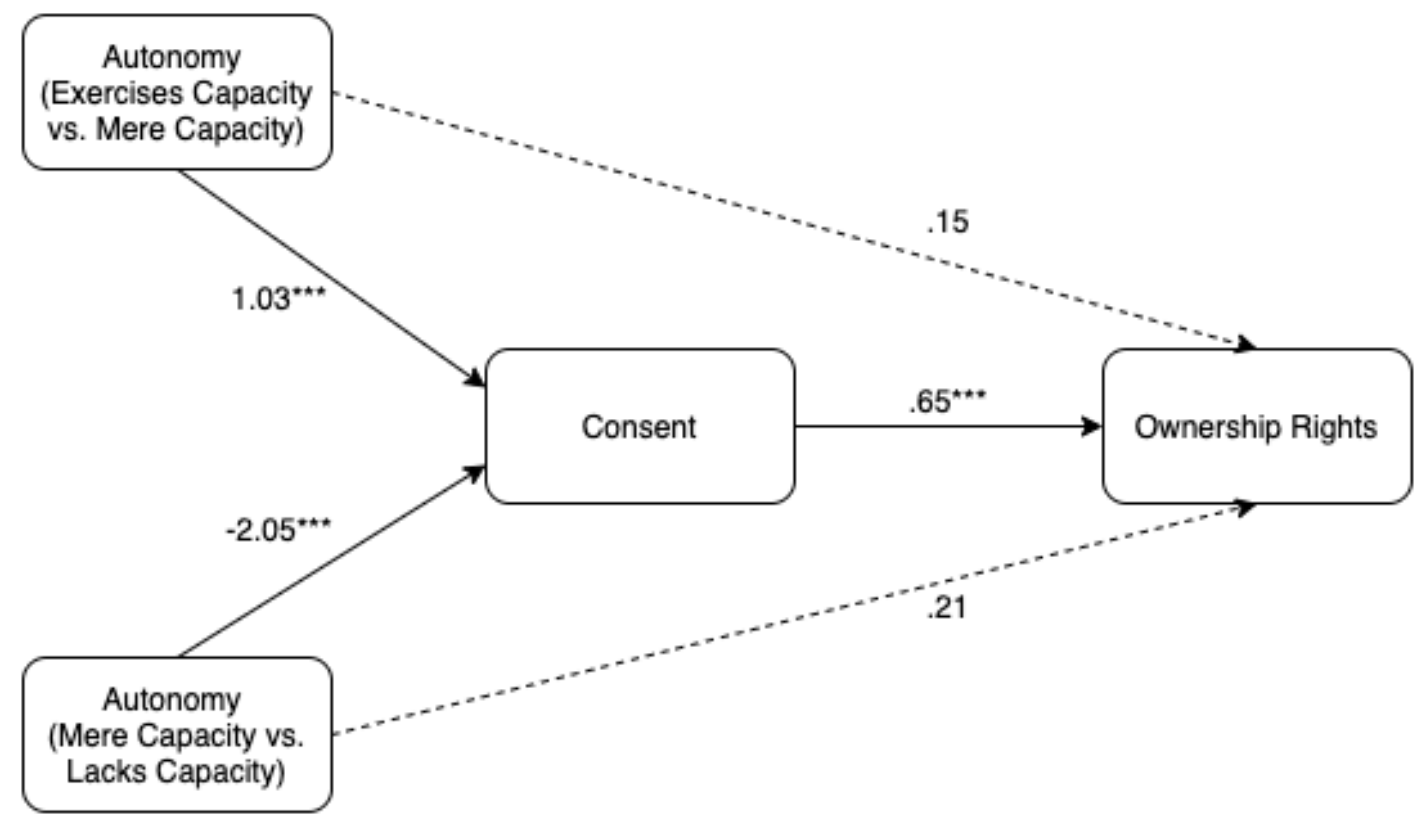

Figure 5. Mediation model showing that the effect of autonomy condition on judgments of ownership rights was fully mediated by the effect of autonomy condition on judgments of valid consent. Unstandardized regression coefficients are shown for each path. Asterisks indicate statistically significant relationships, $* * *=p<.001$. Dotted arrows indicate nonsignificant relationships.

Consistent with our pre-registered analyses, we used linear regression to assess whether judgments of valid consent predicted transfer of ownership rights independently of the effect of autonomy condition. The regression confirmed that they did, $b=-0.80, S E=.10, t=-8.16$, $p<.001$, CI [-0.99, -0.61$]$.

To further explore the relationship between judgments of valid consent and judgments of ownership rights, we conducted an exploratory multicategorical mediation analysis using Process v. 3.5, Model 4, with 10,000 bootstrapped samples (see Hayes, 2012; Hayes \& Preacher, 2014) and 95\% bias-corrected confidence intervals for indirect effects. Autonomy condition was entered as the independent variable and ownership rights judgments as the dependent variable, with consent judgments as the mediator. Results suggested that judgments of valid consent fully mediated the effect of Autonomy on judgments of ownership rights (see Table 3 and Figure 5).

\begin{tabular}{|c|c|c|c|c|c|}
\hline Autonomy condition & & $b$ & S.E. & 95\% C.I. & $p$ \\
\hline \multirow{3}{*}{$\begin{array}{c}\text { Exercises Capacity vs. } \\
\text { Mere Capacity }\end{array}$} & Indirect & .67 & .20 & $.28,1.06$ & - \\
\hline & Direct & .15 & .24 & $-.32, .62$ & .538 \\
\hline & Total & .82 & .30 & $.22,1.41$ & .008 \\
\hline
\end{tabular}




$\begin{array}{cccccc}\begin{array}{c}\text { Mere Capacity vs. } \\ \text { Lacks Capacity }\end{array} & \text { Indirect } & -1.32 & .24 & -1.83,-.88 & - \\ & \text { Direct } & -.21 & .24 & -.69, .27 & .394 \\ & \text { Total } & -1.53 & .28 & -2.08,-.98 & <.001\end{array}$

Table 3. $b$ shows unstandardized indirect, direct, and total effects of Autonomy condition on ownership rights via consent, with the Mere Capacity condition as the baseline for comparison, with standard errors and $95 \%$ confidence intervals.

\subsection{Discussion}

Study 3 demonstrated that the impact of autonomy on judgments of valid consent has important downstream consequences for the allocation of rights and obligations to others, here under the category of "ownership rights." When participants judged that consent to a sale was not valid, they judged that the buyer had no right to the item, that it was her moral duty to give it back, and that she should be forced to return it. By contrast, when participants judged that consent to a sale was valid, they judged that the buyer was morally permitted to keep the item, had no duty to return it, and should not be forced to return it.

Importantly, participants' perceptions of ownership rights appeared to be independent of their general moral judgments of the rightness or wrongness of the consented-to action. In this case, whether or not consent was valid transformed the perceived rights and obligations of an innocent third party (the buyer, Melanie), even though she was not involved in the acquisition of consent, had no reason to suspect that the relevant consent was compromised, was not culpable for any wrongdoing in the original consent transaction, and indeed did not have any reason to suspect any wrongdoing.

Furthermore, moral assessment of the actions of the consent-obtainer (Sam, the seller) came apart from judgments of the validity of the consent: moral judgments, but not judgments of valid consent, were strongly affected by whether the consenter exercised her capacities to make her decision in an autonomous manner. So, while Sam's selling the bracelet was considered somewhat morally permissible in the Exercises Capacity condition, it was considered morally wrong in the Mere Capacity condition, where the consenter was rash and failed to decide in a rational or authentic manner even though she had the mental capacity to do so. By contrast, agreement that the consent was valid remained well above midpoint in both the Exercises Capacity and Mere Capacity conditions.

As in Studies 1 and 2, judgments of whether consent was valid in the first place were largely driven by the extent to which the agent possessed the capacity to make autonomous decisions at the time of deciding. While participants showed slightly lower levels of agreement that the Mere Capacity agent gave valid consent compared to the Exercises Capacity agentunlike in Studies 1 and 2 -in both conditions, agreement remained above midpoint. By contrast, ratings of valid consent dropped well below midpoint in the Lacks Capacity condition.

The finding the Mere Capacity agent's failure to decide in an autonomous manner slightly lowered perceptions of valid consent differed from predictions and from the results of Studies 1 and 2. Two possibilities could account for this inconsistency. 
On the one hand, it's possible that the exercise of autonomous decision-making directly promotes perceptions of the degree to which consent is valid some circumstances, even though it is not normally regarded as necessary for moral transformation to take place (the decision of the Mere Capacity agent was regarded as morally transformative). We speculate that this could especially be the case when participants are less confident overall about whether the interaction is consensual-perhaps because the person asking for consent appears to be exploiting or coercing the consenter.

On the other hand, it's likely that whether an agent exercises their autonomous decisionmaking capacities is itself used as a cue to make judgments about whether the agent possesses autonomous capacities, which in turn drives judgments of the validity of their consent. For example, whether a person behaves rationally affects the extent to which they are inferred to have the capacity to behave rationally. Supporting this interpretation, we observed the same pattern both for judgments of valid consent and for judgments of the agent's capacities: unlike in Studies 1 and 2, our manipulation checks showed that participants were less inclined to agree that the Mere Capacity agent really did have the capacity for rational and authentic choice to the same extent as they agreed that Exercises Capacity agent did. Although the vignette stated that the Mere Capacity agent possessed these capacities, participants may have been more uncertain about the true extent of these capacities, given that the agent was in a vulnerable context (i.e., recovering from surgery in hospital) and there was no further explanation for why they did not make a better decision. This was reflected in exploratory data we collected in which we asked participants to justify their answers, as a number of participants who were in the Mere Capacity condition but disagreed that the agent gave valid consent said they did not truly believe that the agent's capacity to choose was unimpaired. For example, one participant wrote that "[r]egardless of what was said about Jessica being in her right mins [sic] it was obvious that she wasn't". A number of others suggested that situational factors would have undermined the agent's capacity. For example, one participant wrote, "I think that Jessica was in a stressful experience...I know that she is not on any mind altering medications, but surgery itself is a lot to handle"; another wrote, "Jessica is in the hospital recovering from surgery. Even if her medication isn't getting in the way of her thinking, her situation will certainly have worn her down and exhausted her."

\section{General Discussion}

The present studies investigated the folk concept of valid consent and its relationship to autonomy. Study 1 showed that when agents lack autonomous decision-making capacities, participants are less likely to view their consent as valid, while simply failing to exercise these capacities does not undermine perceived valid consent. Study 2 showed that failing to exercise autonomous decision-making in various concrete ways (e.g., giving in to impulse) similarly failed to reduce judgments of valid consent, even when it led the agent to make a choice that was not right for them. Again, however, lacking the capacity to make autonomous decisions (e.g., lacking the capacity to resist impulses) did reduce judgments that consent was valid. Finally, Study 3 showed that these consent judgments carry significant downstream consequences for judgments of ownership rights.

Our studies therefore suggest that the folk concept, like academic treatments, links the validity of consent to the autonomy of the agent. Specifically, across three studies, we found consistent evidence that consent is regarded as less valid when the agent's autonomous decision-making capacities are impaired or lacking. 
By contrast, the observed relationship between judgments of valid consent and the exercise of autonomous capacities was inconsistent. While we did not find strong evidence for the claim that there is no relationship between exercising autonomy and judgments of valid consent, participants tended to treat the Mere Capacity agent's consent as equally valid (Study 2) or slightly more valid (Study 1) compared to someone deciding in a fully autonomous manner; this was so even when the Mere Capacity agent was regarded as making their decision irrationally and without regard for their own values, and as doing something that wasn't right for them.

An exception was Study 3, where we found that participants treated a competent agent's consent as slightly less valid when the vignette stated that they failed to decide in an autonomous way. However, this result coincided with doubt that the Mere Capacity agent in this scenario really did have the capacity to decide autonomously, as revealed by participants' responses to the manipulation-check questions. Furthermore, the agent's possession of autonomous capacities played a stronger role in driving consent judgments: while the Mere Capacity agent was still viewed, on average, as giving valid consent overall, judgments of consent were dramatically reduced when it was stated that the agent lacked these capacities altogether, in which case participants no longer tended to judge that consent was valid.

On balance, then, we found little support for the Exercises Capacity Hypothesis, according to which the validity of consent is generally determined by whether an agent decides in an autonomous (rational, authentic) manner. Although Study 3 suggests that there may be specific circumstances in which the exercise of autonomous decision-making enhances perceptions that consent is valid, our study findings provide stronger support for a moderate Mere Capacity Hypothesis, according to which morally transformative consent normally only depends on whether an agent possesses the capacity to make autonomous decisions, irrespective of whether the decision to consent is in fact made autonomously. Of course, this finding is consistent with the possibility, to be explored in further research, that whether an agent decides in a rational or authentic manner may well affect perceptions of valid consent indirectly, since irrational, inauthentic or otherwise poor decision-making may be a cue that an agent's capacity to decide autonomously is lacking or constrained.

Thus, we find that folk reasoning about valid consent differs from standard treatments in medical ethics and moral philosophy that require, not only that the agent has autonomous capacities, but also that consent decisions be formed in an autonomous way. At the same time, our findings suggest that the folk concept of consent mirrors expert treatments in the sense that the transformation of rights and obligations depends on the provision of consent by an autonomous agent.

\subsection{The Role of Autonomous Consent in Moral Cognition}

Our findings suggest that consent judgments based on the possession of autonomous capacities come apart from judgments of the moral wrongness of acting on that consent, instead playing a nuanced role in downstream moral reasoning about rights and obligations.

We therefore suggest that making autonomous decisions (i.e., exercising autonomous capacities), on the one hand, and possessing autonomous capacities, on the other, play importantly different roles in moral reasoning about consent transactions. 
On the one hand, our studies suggest that whether an agent makes a decision in an autonomous way affects whether their choice is thought likely to be good for them. It is thus relevant to assessing whether others are doing something morally wrong when they act on this decision. For instance, in Study 3, Sam was judged to have done something wrong when he acted on Jessica's consent to sell the bracelet even though he knew she didn't make the decision in a rational, authentic way and would regret it. This finding is consistent with a large literature showing that breaking moral norms, harming others, and knowingly causing harmful consequences affect judgments that a person is doing something morally wrong. More broadly, this result suggests that the exercising autonomous decision-making-while not relevant to participants' assessments of valid consent - is relevant to their morally evaluative appraisals. This result coheres with the dominant framework of research in moral cognition, which focuses on how people generate morally evaluative appraisals of moral agents (especially potential wrongdoers) within agent-victim or agent-beneficiary dyads. This wide literature has explored how intentions, consequences and norms affect judgments of the rightness or wrongness of actions (Crockett, 2013; Cushman \& Greene, 2012; Greene, 2008; Graham et al 2013; Gray, Young \& Waytz 2012), the agent's blameworthiness or praiseworthiness (Alicke, 2000; Malle, Guglielmo, \& Monroe, 2014), the moral agent's character (Uhlmann, Pizarro \& Diermeier, 2015), and the agent's relation to good or bad outcomes (Knobe, 2003).

Our findings underscore that these types of moral appraisals are psychologically distinct from judgments of valid consent. Judgments of the validity of consent came apart from appraisals of whether the consenter and consent-obtainer were acting rightly or wrongly, making good or poor decisions, or acting in praiseworthy or blameworthy ways. Consent judgments had a different function: a core finding of Study 3 was that the provision of autonomous, valid consent crucially affected judgments of what other third parties were and were not permitted to do. Specifically, the character who selfishly got a friend to agree to selling her bracelet was perceived to be doing something morally wrong across all conditions. Nevertheless, variations in the validity of consent determined whether ownership was in fact transferred, whether the buyer was regarded as morally permitted to keep the item, and whether the state was permitted to forcibly stop or reverse the transaction. This finding not only contributes to prior work on reasoning about ownership (Friedman, Neary, Defeyter \& Malcolm, 2011), it also illuminates the importance of autonomous capacities and valid consent to moral reasoning about the rights and duties of third parties. This is a moral dimension not captured by existing work on moral appraisals of actions or character within the agent-patient dyad.

We suggest, therefore, that the possession of autonomous capacities, and corresponding judgments of valid consent, may play an important role in whether people's decisions are treated as authoritative. If agents possess autonomous capacities, they have not only the ability but the right to make their own decisions $;{ }^{9}$ this status means that others are required to respect their decisions and refrain from intervening when they consent, even if intervening would be in the consenter's best interest. On the other hand, if an agent lacks autonomous capacities,

\footnotetext{
${ }^{9}$ This phenomenon raises interesting questions about possible limits on the kinds of things to which autonomous agents are able to give valid consent, such as whether an autonomous agent is able to make a morally authoritative decision to give up their right to make decisions for themselves - as in consensually opting into slavery. Studies by Starmans and Friedman (2016) suggest that agents are not viewed as ownable to the extent that they are autonomous, but that an autonomous agent may be viewed as somewhat "owned" if they consent to being owned (Starmans and Friedman, 2016, Study 4). Future research could examine to what extent, and in what way precisely, such consent is viewed as valid and morally transformative, if at all. We thank an anonymous reviewer for this suggestion.
} 
third parties may regard the consenter's "decision" as something to be ignored, allowing them to paternalistically intervene for the consenter's own good.

Future research might investigate whether this phenomenon extends to domains other than ownership. For instance, imagine that A is immorally trying to get B to have unprotected sex, where this isn't what B wants, and A doesn't care about B's wishes, desires, or welfare. We would expect participants to judge that $\mathrm{A}$ is doing something morally wrong. However, a crucial difference may emerge between the case where $\mathrm{B}$ has the capacity to make an autonomous decision but fails to exercise these capacities and the case where B lacks these capacities altogether (e.g., because they are cognitively impaired, too young, too intoxicated, or A exerts coercive pressure). In the latter case, we might expect participants to judge that B's consent is not valid, and that it would therefore be permissible, or perhaps obligatory, for third parties to attempt to protect B by physically intervening to prevent them from having sex with A. By contrast, in the case where B is competent but gives consent irrationally, without accounting for the consequences or their personal desires, we might expect participants to judge that third parties must respect B's decision-even if it's the wrong decision, and even if A is immorally taking advantage of B. Moreover, we would expect participants to judge that it would be immoral for third parties to forcibly prevent B from having sex with A (although they may attempt to warn B or persuade B to change their mind).

The disjuncture between moral permissibility and valid consent that we documented in Study 3 may illuminate prior research about consent-by-deception which shows that even when someone is intentionally deceived into saying "yes" to things like sex or surgery, participants tend to judge the interaction to be consensual (Sommers, 2020). Although the consenters in Sommers's vignettes were deceived, they retained normal capacities to reason and make decisions. Furthermore, they were not forced to believe the deceiver's testimony or prevented from checking the information they were being given. While further research is needed, it's plausible that deception did not affect participants' perception that the consenter was in full possession of their psychological capacity to make rational and authentic choices-even though the deception meant that the choice they made did not objectively satisfy their desires. If so, our finding that only the capacity to make autonomous decisions is important for valid consent could partly explain participants' judgments that such interactions are consensual. Furthermore, our findings suggest that participants did not necessarily think that deception was morally permissible just because they judged the interaction to be consensual. Instead, it's plausible that participants judged that consent-by-deception was valid even though they also judged that the deceiver's actions were morally wrong, where the former judgment may have affected downstream moral reasoning (e.g., about what kinds of punishment are appropriate for the deceiver).

It may be that consent is regarded as valid only if the consenter is responsible for their decision to consent. Just as agents are not regarded as forfeiting rights (i.e. being subject to punishment) when they are not regarded as morally responsible for harmful behavior, so, perhaps, agents are not regarded as transforming their own rights when they are not responsible for the decision to do so. Previous work has shown that a central component of moral responsibility is the agent's ability to choose, which is determined in part by the possession of cognitive and psychological capacities for rational decision-making (Alicke, 2000; Malle, Guglielmo, \& Monroe, 2014; Schlenker et al., 1994; Shaver, 1985; Weiner, 1995). Accordingly, lacking autonomous decision-making capacities reduces judgments that an agent is morally responsible (Blakey \& Kremsmayer, 2018; Daigle \& Demaree-Cotton, 2021; Monroe, Brady \& Malle, 2017, Study 4; Rise \& Halkjelsvik 2019). Similar patterns are seen 
in lay judgments of criminal responsibility (e.g. Allen et al., 2019). Future research could explore the link between judgments of autonomous capacity consent and judgments of responsibility.

Finally, a core finding of the present studies was that the relationship between autonomous decision-making capacities and judgments of valid consent held across a variety of domainsincluding sexual consent, medical consent, consent to entry and search, and consent to property transfer. This provides novel evidence that people possess a domain-general moral concept of autonomous, valid consent that they employ across very different domains. The apparent domain-generality of reasoning about autonomous, valid consent further supports our contention that consent forms an important but heretofore relatively neglected component of moral cognition.

\subsection{Limitations}

We used vignettes that explicitly manipulated information about the consenter's autonomy. In real life, however, people often lack access to explicit information about an agent's decision-making capacities. Instead, it's likely that they infer such information from what is known about the consenter's circumstances, behavior and environment. Relevant cues could include age, mental illness, developmental disability, intoxication, history of trauma or abuse, the consenter's past behaviors, displays of emotion or pain, or social group stereotypes (e.g. Blakey \& Kremsmayer, 2018; Vonasch, Baumeister, \& Mele, 2018). Future research could further investigate which kinds of real-life circumstances are regarded as autonomy- and consent-undermining. For example, future research could examine whether, and in what circumstances, intoxication is regarded as undermining an agent's capacity for autonomous decision-making and therefore their ability to give valid consent, as opposed to being perceived as a state that merely leads competent agents to make bad decisions, without affecting the validity of their consent.

Relatedly, Study 3, in which an agent was temporarily incapacitated due to medication, yielded much lower ratings of valid consent and autonomy than did Studies 1 and 2, in which the agent's lack of decision-making capacity was unexplained. The lower ratings in Study 3 is likely due to the fact that the incapacity was wholly general (they were unable to engage in any kind of autonomous reasoning or decision-making), and was explained by a concrete condition (heavy medication). In Study 2, the agent in Lacks Capacity lacked a specific component of autonomous decision-making capacity (for example, lacking the ability to control impulses), while in Study 1, the incapacity was generalized but not explained by any concrete condition. In addition, unlike in Studies 1 and 2, the incapacity in Study 3 was temporary, not a permanent condition.

Finally, while the present studies suggest that possessing autonomous decision-making capacities, but not exercising those capacities, is necessary for judgments that consent is valid, we do not expect that this is sufficient. For instance, in addition to the possession of autonomous capacities, valid consent likely requires that "yes" is explicitly or implicitly communicated, and that the agent's decision is free from external interference such as coercion. Further research is needed to examine other necessary conditions for judgments of valid consent.

\subsection{Implications for public health and policy}


Our research suggests that consent education and anti-sexual-violence campaigns may be more successful to the extent that the emphasize the way that alcohol, pressure, or manipulation undermine the consenter's capacity to make an autonomous decision rather than focusing on how they impair the quality of decisions (cf. Beres, 2014; Bonnefon, Shariff, \& Rahwan, 2020). Secondly, our findings suggest that sex may be regarded as consensual even if one party is wronging the other (Study 3), even if sex is not the right choice for the consenter (Studies 1 and 2), and even if sex is influenced by unwanted impulse, peer pressure, or irrational belief (Study 2). Therefore, policies and educational campaigns may be more successful in targeting harmful and immoral behaviors by not only appealing to "consent" but to additional moral concepts as well (e.g., respect, care, harm; see Carmody, 2005; Carmody \& Ovenden, 2013). Finally, our findings may also inform research on victim-blaming (Niemi \& Young, 2014, 2016), in that victim-blaming narratives may capitalize on the role of autonomous capacity in valid consent. Emphasizing the victim's capacities to make their own decisions may contribute to the assignment of moral obligations to victims to avoid sexual defilement, judgments that they have the capacity to avoid defilement, and judgments of causal responsibility for sexual assault, all of which contribute to ascriptions of moral responsibility to victims (Niemi \& Young, 2014). More than that, however, our findings suggest that emphasis on the consenter's capacities may result in inappropriate judgments that the assault was consensual, protecting the assaulter from third party punishment and interference even if they are regarded as morally responsible for wrongdoing.

\section{Conclusion}

Before these studies, it remained an open possibility that "valid consent" as a rich and normatively complex force existed only as a technical concept used in philosophical, legal and academic domains. We found, however, that the folk concept of consent involves normative distinctions between valid and invalid consent that are sensitive to the consenter's autonomy, even if the linguistic utterance of "yes" is held constant, and that this concept plays an important role in moral reasoning.

Specifically, the studies presented here examined the relationship between autonomy and intuitive judgments of valid consent in several domains: medical procedures, sexual relations, police searches, and agreements between buyers and sellers. Across scenarios, we found that judgments of valid consent carried a specific relationship to autonomy: whether an agent possesses the mental capacity to make decisions in an autonomous way has a consistent impact on whether their consent is regarded as valid, and thus whether it was regarded as morally transformative of the rights and obligations of the consenter and of third parties. Yet, whether the agent in fact makes their decision in an autonomous, rational way-based on their own authentic values and what is right for them-has little impact on perceptions of consent or associated rights, although it has relevance for whether the consent-obtainer is acting wrongly. Autonomy thus has a subtle role in the ordinary reasoning about morally transformative consent, where consent given by an agent with autonomous capacities has a distinctive role in downstream moral reasoning. 


\section{Declaration of Competing Interest}

None.

\section{Acknowledgements}

We would like to thank Joshua Knobe for comments and discussion on multiple drafts. In addition we would like to thank: Mario Attie, April Bailey, Michael Dunn, Brian Earp, Shelly Kagan, Matthew Lindauer, Jonathan Pugh, Julia Rubin, Mark Sheehan, and Gideon Yaffe; members of Yale's Philosophical Psychology lab and the Chicago/Michigan Psychology and Lab Studies Group; audiences at the Yale-Oxford BioXphi Conference, the European Online Experimental Philosophy Conference, Michigan's Mind and Moral Psychology Research Group, the Group for Empirical Approaches to Morality and Society, and the Ethox Centre and Wellcome Centre for Ethics and Humanities Seminar Series. This research received funding support from the Wachtell Program in Behavioral Law, Economics \& Finance at the University of Chicago Law School and the Institute for Citizens \& Scholars.

\section{References}

Alicke, M. D. (2000). Culpable control and the psychology of blame. Psychological Bulletin $126,556-574$.

Allen, C. H., Vold, K., Felsen, G., Blumenthal-Barby, J. S., \& Aharoni, E. (2019). Reconciling the opposing effects of neurobiological evidence on criminal sentencing judgments. PLoS ONE 14(1): e0210584. https://doi.org/10.1371/journal. pone. 0210584

Appelbaum, P. S., \& Roth, L. H. (1982). Competency to consent to research. A psychiatric overview. Archives of General Psychiatry, 39, 951-958.

Bates, D., Maechler, M., Bolker, B., \& Walker, S. (2014). lme4:Linear mixed-effects models using eigen and $\mathrm{s} 4$. $R$ package version $1(7), 1-23$.

Baumeister, R. F., \& Monroe, A. E. (2014). Recent Research on Free Will: Conceptualizations, Beliefs, and Processes. Advances in Experimental Social Psychology, 50, 1-52.

Beauchamp, T. L. (2010). Autonomy and consent. In F. Miller \& A. Wertheimer (Eds.), The ethics of consent: Theory and practice (pp. 55-78) New York, NY: Oxford University Press.

Beauchamp, T. L., \& Childress, J. F. (2013). Principles of Biomedical Ethics ( $7^{\text {th }}$ Edition). Oxford: Oxford University Press.

Beres, M. A. (2014). Rethinking the concept of consent for anti-sexual violence activism and education. Feminism \& Psychology, 24(3), 373-389.

Berg, J. W., Appelbaum, P. S., Lidz, C. W., \& Meisel, A. (2001). Informed Consent: Legal Theory and Clinical Practice (2nd edition), New York: Oxford University Press. 
Blakey, R., \& Kremsmayer, T. P. (2018). Unable or Unwilling to Exercise Self-control? The Impact of Neuroscience on Perceptions of Impulsive Offenders. Frontiers in Psychology, 8, 2189. DOI: 10.3389/fpsyg.2017.02189

Blum, G., Bourdeau, J., Eclavea, R. P., Holben, J., Oakes, K., \& Surette, E. C. (2021). Fraud and Deceit, American Jurisprudence (2nd ed).

Bohns, V. K. (in press). Toward a psychology of consent. Psychological Science.

Bonnefon, J.F., Shariff, A., \& Rahwan, I. (2020). The moral psychology of AI and the ethical opt-out problem. In M. Liao (Ed.), The Ethics of Artificial Intelligence. Oxford: Oxford University Press. (pp.109-126).

Carmody, M. (2005). Ethical erotics: Reconceptualizing anti-rape education. Sexualities, $8(4), 465-480$.

Carmody, M., \& Ovenden, G. (2013). Putting ethical sex into practice: Sexual negotiation, gender and citizenship in the lives of young women and men. Journal of Youth Studies, 16(6), 792-807.

Chakroff, A., \& Young, L. (2015). How the mind matters for morality. AJOB Neuroscience, $6(3),, 41-46$.

Crockett, M. (2013). Models of morality. Trends in Cognitive Sciences 17(8), 363-366.

Cushman, F. A., \& Greene, J. D. (2012). Finding faults: How moral dilemmas illuminate cognitive structure. Social Neuroscience, 7(3), 269-279.

Deci, E. L., \& Ryan, R. M. (2000). The "What" and "Why" of goal pursuits: Human needs and the self-determination of behavior. Psychological Inquiry: An International Journal for the Advancement of Psychological Theory, 11(4), 227-268.

Deci, E. L., \& Ryan, R. M. (2009). Self-determination theory: A consideration of human motivational universals. In P. J. Corr \& G. Matthews (Eds.), The Cambridge handbook of personality psychology (pp. 441-456). New York, NY: Cambridge University Press.

Dougherty, T. (2013). Sex, lies, and consent. Ethics, 123, 717-744.

Dougherty, T. (2019). Why does duress undermine consent? NOÛS, 1-17. https://doi.org/10.1111/nous.12313

Espinosa, J., \& Starmans, C. (2020). Control it and it is yours: Children's reasoning about the ownership of living things. Cognition, 202, 104319.

Faden, R. R., \& Beauchamp, T. L. (1986). A history and theory of informed consent. New York: Oxford University Press.

Feltz, A., \& Cova, F. (2014). Moral responsibility and free will: A meta-analysis. Consciousness and Cognition, 30, 234-246. 
Friedman, O., Neary, K. R., Defeyter, M. A., \& Malcolm, S. L. (2011). Ownership and object history. In H. Ross \& O. Friedman (Eds.), Origins of ownership of property. New Directions for Child and Adolescent Development, 132, 79-89.

Graham, J., Haidt, J., Koleva, S., Motyl, M., Iyer, R., Wojcik, S. P., \& Ditto, P. H. (2013). Moral foundations theory: The pragmatic validity of moral pluralism. Advances in Experimental Social Psychology, 47, 55-130.

Gravelin, C. R, Biernat, M., \& Bucher, C. E. (2019). Blaming the victim of acquaintance rape: Individual, situational, and sociocultural factors. Frontiers in Psychology, 9: 2422. https://doi.org/10.3389/fpsyg.2018.02422

Gray, K., Young, L., \& Waytz, A. (2012). Mind perception is the essence of morality. Psychological Inquiry, 23, 101-124.

Greene, J. D. (2008). The secret joke of Kant's soul. In W. Sinnott-Armstrong, \& C. B. Miller (Eds.), Moral psychology: The neuroscience of morality: Emotion, brain disorders, and development. Cambridge, MA: MIT Press (pp. 35-79).

Haidt, J., Bjorklund, F., \& Murphy, S. (2000). Moral dumbfounding: When intuition finds no reason. Lund Psychological Reports, 2, 1-23.

Hammond, E. M., Berry, M. A., \& Rodriguez, D. N. (2011). The influence of rape myth acceptance, sexual attitudes, and belief in a just world on attributions of responsibility in a date rape scenario. Legal and Criminological Psychology, 16(2), 242-252.

Hayes, A. (2012). PROCESS: A versatile computational tool for observed variable mediation, moderation, and conditional process modeling [White paper]. Retrieved from http://www.afhayes.com/public/process2012.pdf

Hayes, A., \& Preacher, K. (2014). Statistical mediation analysis with a multicategorical independent variable. British Journal of Mathematical and Statistical Psychology, 67, 451-470.

Henne, P., Niemi, L., Pinillos, Á., De Brigard, F., \& Knobe, J. (2019). A counterfactual explanation for the action effect in causal judgment. Cognition, 190, 157-164.

Hohfeld, W. N. (1913). Some Fundamental Legal Conceptions as Applied in Judicial Reasoning. The Yale Law Journal, 23(1), 16-59.

Hosmer, L. T. (1995). Trust: The Connecting Link Between Organizational Theory and Philosophical Ethics. Academy of Management Review, 20(2), 379-40.

Humphreys, T.P. and Herold, E. (2003). Should universities and colleges mandate sexual behavior? Student perceptions of Antioch College's consent policy. Journal of Psychology \& Human Sexuality, 15(1), 35-51.

Hurd, H. (1996). The moral magic of consent. Legal Theory, 2, 121-146. 
Jozkowski, K. N., Peterson, Z. D., Sanders, S. A., Dennis, B., \& Reece, M. (2014). Gender differences in heterosexual college students' conceptualizations and indicators of sexual consent: Implications for contemporary sexual assault prevention education. Journal of Sex Research, 51, 904-916. DOI: 10.1080/00224499.2013.792326

Kahan, D. M. (2010). Cultural, cognition, and consent: Who perceives what, and why, in acquaintance-rape cases. University of Pennsylvania Law Review, 158(3), 729-813.

Knobe, J. (2003). Intentional action and side effects in ordinary language. Analysis, 63(3), 190-194.

Kuznetsova, A., Brockhoff, P. B., \& Christensen, R. H. B. (2017). lmerTest Package: Tests in Linear Mixed Effects Models. Journal of Statistical Software, 82(13), 1-26.

Lim, G. Y., \& Roloff, M. E. (1999) Attributing sexual consent, Journal of Applied Communication Research, 27(1), 1-23. DOI: 10.1080/00909889909365521

Malle, B. F, Guglielmo, S., \& Monroe, A. E. (2014). A Theory of Blame. Psychological Inquiry, 25(2) 147-186, DOI: 10.1080/1047840X.2014.877340

Marg, L. Z. (2020). College Men's Conceptualization of Sexual Consent at a Large, Racially/Ethnically Diverse Southern California University. American Journal of Sexuality Education, 5(3), 371-408, DOI: 10.1080/15546128.2020.1737291

Mele, A. (1995). Autonomous Agents: From Self-Control to Autonomy. New York: Oxford University Press.

Millar, J. C., Turri, J., \& Friedman, O. (2014). For the greater goods? Ownership rights and utilitarian moral judgment. Cognition, 133, 79-84.

Monroe, A. E., Brady, G. L., \& Malle, B. F. (2017). This isn't the free will worth looking for: General free will beliefs do not influence moral judgments, agent-specific choice ascriptions do. Social Psychological and Personality Science, 8(2), 191-199. DOI: $10.1177 / 1948550616667616$

Moye, J., Gurrera, R. J., Karel, M. J., Edelstein, B., \& O'Connell, C. (2006). Empirical advances in the assessment of the capacity to consent to medical treatment: Clinical implications and research needs. Clinical Psychology Review, 26, 1054-1077.

Muehlenhard, C. L., Humphreys, T. P., Jozkowski, K. N., \& Peterson, Z. D. (2016) The Complexities of Sexual Consent Among College Students: A Conceptual and Empirical Review. The Journal of Sex Research, 53(4-5), 457-487. DOI: $\underline{10.1080 / 00224499.2016 .1146651}$

Neary, K. R., Friedman, O., \& Burnstein, C. L. (2009). Preschoolers infer ownership from "control of permission". Developmental Psychology, 45(3), 873-876.

Neff, K. D. (2001) Judgments of personal autonomy and interpersonal responsibility in the context of Indian spousal relationships: An examination of young people's reasoning 
in Mysore, India. British Journal of Developmental Psychology, 19, 233-257.

DOI: $\underline{10.1348 / 026151001166056}$

Niemi, L., \& Young, L. (2014). Blaming the victim in the case of rape. Psychological Inquiry, 25, 2, 230-233.

Niemi, L., \& Young, L. (2016). When and why we see victims as responsible: The impact of ideology on attitudes toward victims. Personality and Social Psychology Bulletin, 42(9), 1227-1242.

Peace, K. \& Valois, R. (2014). Trials and tribulations: Psychopathic traits, emotion, and decision-making in an ambiguous case of sexual assault. Psychology, 5, 1239-1253. DOI: $10.4236 /$ psych.2014.510136.

Peter-Hagene, L. C., \& Ratliff, C. L. (2020). When jurors' moral judgments result in jury nullification: moral outrage at the law as a mediator of euthanasia attitudes on verdicts. Psychiatry, Psychology and Law, DOI: 10.1080/13218719.2020.1751741

Pugh, J. (2020). Autonomy, Rationality and Contemporary Bioethics. Oxford: Oxford University Press.

Rise, J., \& Halkjelsvik, T. (2019). Conceptualizations of addiction and moral responsibility. Frontiers in Psychology, 10, 1483. DOI: 10.3389/fpsyg.2019.01483

Rerick P.O., Livingston T.N., Davis D. (2019) Rape and the Jury. In: W. O'Donohue W., \& P. Schewe (Eds.), Handbook of sexual assault and sexual assault prevention. Springer, Cham. https://doi.org/10.1007/978-3-030-23645-8_33

Rodríguez-Arias, D., Rodríguez López, B., Monasterio-Astobiza, A., \& Hannikainen, I. R. (2020). How do people use 'killing', 'letting die' and related bioethical concepts? Contrasting descriptive and normative hypotheses. bioethics, 34(5), 509-518.

Rozin, P., Lowery, L., Imada, S., \& Haidt, J. (1999). The CAD triad hypothesis: A mapping between three moral emotions (contempt, anger, disgust) and three moral codes (community, autonomy, divinity). Journal of Personality and Social Psychology, 76, 574-586. doi:10.1037/0022-3514.76.4.574

Schlenker, B. R., Britt, T. W., Pennington, J., Murphy, R., \& Doherty, K. (1994). The triangle model of responsibility. Psychological Review, 101, 632-652. doi: 10.1037/0033-295X.101.4.632

Schmidt, M. F. H., Rakoczy, H., \& Tomasello, M. (2013). Young children understand and defend the entitlements of others. Journal of Experimental Child Psychology, 116, 930-944.

Shaver, K. G. (1985). The Attribution of Blame: Causality, Responsibility, and Blameworthiness. New York, NY: Springer.

Shweder, R. A., Much, N. C., Mahapatra, M., \& Park, L. (1997). The "big three" of morality (autonomy, community, divinity) and the "big three" explanations of suffering. In A. 
M. Brandt \& P. Rozin (Eds.), Morality and health (pp. 119-169). Taylor \& Frances/Routledge.

Sommers, R. (2020). Commonsense consent. The Yale Law Journal, 129(8), 2232-2324.

Starmans, C., \& Friedman, O. (2016). If I am free, you can't own me: Autonomy makes entities less ownable. Cognition, 148, 145-153.

Struchiner, N., Hannikainen, I., \& de Almeida, G. d. FCF. (2020). An experimental guide to vehicles in the park. Judgment and Decision Making, 15 (3), 312-329.

Tobia, K. P. (2022, Forthcoming). Experimental Jurisprudence, 89, University of Chicago Law Review. Available at SSRN: https://ssrn.com/abstract $=3680107$ or http://dx.doi.org/10.2139/ssrn.3680107

Uhlmann, E. L., Pizarro, D. A., \& Diermeier, D. (2015). A Person-Centred Approach to Moral Judgment. Perspectives on Psychological Science, 10 (1), 72-81.

Van de Vondervoort, J. W., \& Friedman, O. (2015). Parallels in preschoolers' and adults' judgments about ownership rights and bodily rights. Cognitive Science, 39, 184-198.

Vonasch, A., Baumeister, R., \& Mele, A. (2018). Ordinary people think free will is a lack of constraint, not the presence of a soul. Consciousness and Cognition, 60, 133-151.

Weiner, B. (1995). Judgments of responsibility: A foundation for a theory of social Conduct. New York, NY: Guilford Press.

Wertheimer, A. (2003). Consent to sexual relations. Cambridge: Cambridge University Press.

Whatley, M. A. (1996). Victim characteristics influencing attributions of responsibility to rape victims: A meta-analysis. Aggression and Violent Behavior, 1(2), 81-95.

Wignall, L., Stirling, J., \& Scoats, R. (2020). UK university students' perceptions and negotiations of sexual consent. Psychology \& Sexuality, DOI: 10.1080/19419899.2020.1859601

Yndo, M. C., \& Zawacki, T. (2020). Factors influencing labeling nonconsensual sex as sexual assault. Journal of Interpersonal Violence, 35, 1803-1827. 


\section{Appendices/Supplemental Online Materials}

\section{Appendix A: Supplemental Analyses}

\section{Study 1 Results, With and Without Exclusions}

Unless noted otherwise, shared superscripts indicate that means do not differ significantly from one another as revealed by fitting a linear mixed model with autonomy condition included as a fixed factor and domain included as a random factor. Significance of fixed effects was assessed via $t$-tests using Satterthwaite's method.

Where an analysis of a dependent variable indicated a significant difference $(p<.05)$ only after exclusions but not before, or vice versa, the analysis is shaded grey.

a. N per condition

\begin{tabular}{|l|l|l|}
\hline & $\begin{array}{l}\text { Before } \\
\text { exclusions }\end{array}$ & $\begin{array}{l}\text { After } \\
\text { exclusions }\end{array}$ \\
\hline Exercises Capacity & $\mathrm{N}=155$ & $\mathrm{~N}=146$ \\
\hline Mere Capacity & $\mathrm{N}=146$ & $\mathrm{~N}=91$ \\
\hline Lacks Capacity & $\mathrm{N}=149$ & $\mathrm{~N}=127$ \\
\hline Total & $\mathbf{N}=\mathbf{4 5 0}$ & $\mathbf{N}=\mathbf{3 6 4}$ \\
\hline $\begin{array}{l}\text { Attention check failure rates differ significantly by } \\
\text { condition, } \chi^{2}(6, N=445)=69.65, p<.001 .\end{array}$ \\
\hline
\end{tabular}

b. Manipulation checks

\begin{tabular}{|c|c|c|}
\hline & $\begin{array}{l}N=450 \text { (before exclusions) } \\
\text { Mean (SD) }\end{array}$ & $\begin{array}{l}N=364 \text { (after exclusions) } \\
\text { Mean (SD) }\end{array}$ \\
\hline \multicolumn{3}{|c|}{$\begin{array}{l}\text { Mean rational capacity rating in each of } 3 \text { conditions } \\
\text { E.g., "Marvin has the ability to make rational decisions." } \\
\text { Our pre-registration states that Lacks Capacity condition will be lower than the other two } \\
\text { conditions on this measure. }\end{array}$} \\
\hline Exercises Capacity & $6.16(1.14), n=155^{\mathrm{a}}$ & $6.29(0.96), n=146^{\mathrm{a}}$ \\
\hline Mere Capacity & $6.03(1.09), n=149^{a}$ & $6.38(0.85), n=91^{\mathrm{a}}$ \\
\hline Lacks Capacity & $2.71(1.72), n=146^{\mathrm{b}}$ & $2.35(1.41), n=127^{b}$ \\
\hline \multicolumn{3}{|c|}{$\begin{array}{l}\text { Mean authentic capacity rating in each of } 3 \text { conditions } \\
\text { E.g., "Marvin has the ability to be true to himself when making decisions." } \\
\text { Our pre-registration states that Lacks Capacity condition will be lower than the other two } \\
\text { conditions on this measure. }\end{array}$} \\
\hline Exercises Capacity & $6.19(1.02), n=155^{\mathrm{a}}$ & $6.32(0.77), n=146^{\mathrm{a}}$ \\
\hline Mere Capacity & $5.85(1.12), n=149^{b}$ & $6.15(0.93), n=91^{\mathrm{a}}$ \\
\hline
\end{tabular}




\begin{tabular}{|c|c|c|}
\hline Lacks Capacity & $3.36(1.82), n=146^{\mathrm{c}}$ & $2.98(1.56), n=127^{b}$ \\
\hline \multicolumn{3}{|c|}{$\begin{array}{l}\text { Mean rational exercise rating in each of } 3 \text { conditions } \\
\text { E.g., "Marvin made this particular decision rationally." } \\
\text { Our pre-registration states that Exercises Capacity condition will be higher than the other } \\
\text { two conditions on this measure. }\end{array}$} \\
\hline Exercises Capacity & $5.88(1.27), n=155^{\mathrm{a}}$ & $5.99(1.15), n=146^{\mathrm{a}}$ \\
\hline Mere Capacity & $3.48(1.84), n=149^{\mathrm{b}}$ & $3.19(1.81), n=91^{\mathrm{b}}$ \\
\hline Lacks Capacity & $2.70(1.63), n=146^{\mathrm{c}}$ & $2.35(1.38), n=127^{\mathrm{c}}$ \\
\hline \multicolumn{3}{|c|}{$\begin{array}{l}\text { Mean authentic exercise rating in each of } 3 \text { conditions } \\
\text { E.g., "When Marvin said 'yes' to having surgery, he was not being true to himself." } \\
\text { (reverse-scored) } \\
\text { Our pre-registration states that Exercises Capacity condition will be higher than the other } \\
\text { two conditions on this measure (once it is reverse-scored). }\end{array}$} \\
\hline Exercises Capacity & $5.67(1.45), n=155^{\mathrm{a}}$ & $5.81(1.31), n=146^{\mathrm{a}}$ \\
\hline Mere Capacity & $3.95(1.67), n=149^{\mathrm{b}}$ & $4.04(1.68), n=91^{\mathrm{b}}$ \\
\hline Lacks Capacity & $3.58(1.38), n=146^{\mathrm{c}}$ & $3.69(1.34), n=127^{b}$ \\
\hline
\end{tabular}

c. Judgments of valid consent

Our preregistration states that we will test whether condition predicts consent, and if so, will conduct pairwise comparisons comparing Mere Capacity to Exercises Capacity, and Mere Capacity to Lacks Capacity.

\begin{tabular}{|l|l|l|}
\hline & \multicolumn{1}{|c|}{$\mathbf{N}=\mathbf{4 5 0}$ (before exclusions) } & \multicolumn{1}{|c|}{$\mathbf{N}=\mathbf{3 6 4}$ (after exclusions) } \\
\hline $\begin{array}{l}\text { Cronbach's alpha for } \\
\text { three consent items }\end{array}$ & 0.71 & 0.74 \\
\hline Mean rating of valid consent (composite measure) in each of 3 conditions \\
\hline Exercises Capacity & $5.87(1.18), n=155^{\mathrm{a}}$ & $5.98(1.08), n=146^{\mathrm{a}}$ \\
\hline Mere Capacity & $5.91(1.16), n=149^{\mathrm{a}}$ & $6.38(0.84), n=91^{\mathrm{b}}$ \\
\hline Lacks Capacity & $4.71(1.39), n=146^{\mathrm{b}}$ & $4.78(1.41), n=127^{\mathrm{c}}$ \\
\hline $\begin{array}{l}\text { Difference between mean consent ratings in each of 3 conditions, adjusting for } \\
\text { vignette domain (random factor) }\end{array}$ & $\begin{array}{l}b=0.05, S E=0.14, t=0.35, p \\
=.73, \mathrm{CI}[-0.23,0.32]\end{array}$ & $\begin{array}{l}b=0.36, S E=0.15, t=2.35, p \\
=.019, \mathrm{CI}[0.06,0.65]\end{array}$ \\
\hline $\begin{array}{l}\text { Exercises Capacity vs. } \\
\text { Mere Capacity }\end{array}$ & $\begin{array}{l}b=-1.21, S E=0.14, t=-8.81, \\
p<.001, \mathrm{CI}[-1.48,-0.94]\end{array}$ \\
\hline $\begin{array}{l}\text { Exercises Capacity vs. } \\
\text { Lacks Capacity }\end{array}$ & \begin{tabular}{l}
$b<.1 .16, S E=0.14, t=-8.32, \mathrm{CI}[-1.44,-0.89]$ \\
\hline
\end{tabular}
\end{tabular}




\begin{tabular}{|l|l|l|}
\hline Mere Capacity vs. & $b=-1.21, S E=0.14, t=-8.58$, & $b=-1.56, S E=0.16, t=-10.05$, \\
Lacks Capacity & $p<.001$, CI $[-1.49,-0.93]$ & $p<.001$, CI $[-1.87,-1.26]$
\end{tabular}

d. Judgments of right choice: e.g., "Having surgery was probably the right choice for Marvin."/“Having sex with Frank was probably the right choice for Ellen."/“Allowing the police officers to search his home was probably the right choice for Johnny."

Our pre-registration states that we predict that comparison between Mere Capacity and Exercises Capacity to be significant, as well as the comparison between Mere Capacity and Lacks Capacity.

\begin{tabular}{|c|c|c|}
\hline & $\mathrm{N}=450$ (before exclusions) & $N=364$ (after exclusions) \\
\hline \multicolumn{3}{|c|}{ Mean right choice rating in each of 3 conditions } \\
\hline Exercises Capacity & $5.03(1.61), n=155^{\mathrm{a}}$ & $5.05(1.57), n=146^{\mathrm{a}}$ \\
\hline Mere Capacity & $4.19(1.57), n=149^{\mathrm{b}}$ & $4.19(1.50), n=91^{\mathrm{b}}$ \\
\hline Lacks Capacity & $3.71(1.78), n=146^{\mathrm{c}}$ & $3.47(1.73), n=127^{\mathrm{c}}$ \\
\hline \multicolumn{3}{|c|}{$\begin{array}{l}\text { Difference between mean right choice ratings in each of } 3 \text { conditions, adjusting for } \\
\text { vignette domain (random factor) }\end{array}$} \\
\hline $\begin{array}{l}\text { Exercises Capacity } \\
\text { vs. Mere Capacity }\end{array}$ & $\begin{array}{l}b=-.82, S E=0.17, t=-4.79, p \\
<.001, \text { CI }[-1.16,-0.49]\end{array}$ & $\begin{array}{l}b=-1.01, S E=0.19, t=-5.43, p \\
<.001, \text { CI }[-1.38,-0.65]\end{array}$ \\
\hline $\begin{array}{l}\text { Exercises Capacity } \\
\text { vs. Lacks Capacity }\end{array}$ & $\begin{array}{l}b=-1.31, S E=0.17, t=-7.58, p \\
<.001, \text { CI }[-1.65,-0.97]\end{array}$ & $\begin{array}{l}b=-1.60, S E=0.17, t=-9.47, p \\
<.001, \text { CI }[-1.93,-1.26]\end{array}$ \\
\hline $\begin{array}{l}\text { Mere Capacity vs. } \\
\text { Lacks Capacity }\end{array}$ & $\begin{array}{l}b=-0.49, S E=0.17, t=-2.79, p \\
=.005, \mathrm{CI}[-0.83,-0.14]\end{array}$ & $\begin{array}{l}b=-0.58, S E=0.19, t=-3.05, p \\
=.002, \mathrm{CI}[-0.96,-0.21]\end{array}$ \\
\hline
\end{tabular}

e. Judgments of morality: "Under these circumstances, it would be morally wrong for the doctor to proceed with the surgery."/ "Under these circumstances, it would be morally wrong for Frank to have sex with Ellen."/ "Under these circumstances it would be morally wrong for the police officers to enter and search Johnny's home. home."

Our pre-registration states that as a secondary analysis, we will test whether morality judgments exhibit the same pattern as consent.

\begin{tabular}{|l|l|l|}
\hline \multicolumn{1}{|c|}{$\mathbf{N}=\mathbf{4 5 0}$ (before exclusions) } & N = 364 (after exclusions) \\
\hline Mean morality rating in each of 3 conditions \\
\hline Exercises Capacity & $2.44(1.79), n=155^{\mathrm{a}}$ & $2.35(1.75), n=146^{\mathrm{a}}$ \\
\hline Mere Capacity & $2.75(1.75), n=149^{\mathrm{a}}$ & $2.14(1.44), n=91^{\mathrm{a}}$ \\
\hline Lacks Capacity & $4.59(1.86), n=146^{\mathrm{b}}$ & $4.54(1.89), n=127^{\mathrm{b}}$ \\
\hline
\end{tabular}




\section{Difference between mean morality ratings in each of 3 conditions, adjusting for}

vignette domain (random factor)

\begin{tabular}{|l|l|l|}
\hline $\begin{array}{l}\text { Exercises Capacity } \\
\text { vs. Mere Capacity }\end{array}$ & $\begin{array}{l}b=.31, S E=0.20, t=1.57, p= \\
0.12, \mathrm{CI}[-0.08,0.07]\end{array}$ & $\begin{array}{l}b=-0.09, S E=0.22, t=-0.42, p \\
=.68, \mathrm{CI}[-0.53,0.34]\end{array}$ \\
\hline $\begin{array}{l}\text { Exercises Capacity } \\
\text { vs. Lacks Capacity }\end{array}$ & $\begin{array}{l}b=2.17, S E=0.20, t=10.88, p \\
<.001, \mathrm{CI}[1.78,2.56]\end{array}$ & $\begin{array}{l}b=2.20, S E=0.20, t=10.99, p \\
<.001, \mathrm{CI}[1.81,2.60]\end{array}$ \\
\hline $\begin{array}{l}\text { Mere Capacity vs. } \\
\text { Lacks Capacity }\end{array}$ & $\begin{array}{l}b=1.86, S E=0.20, t=9.23, p \\
<.001, \mathrm{CI}[1.46,2.25]\end{array}$ & $\begin{array}{l}b=2.30, S E=0.23, t=10.09, p \\
<.001, \mathrm{CI}[1.85,2.75]\end{array}$ \\
\hline
\end{tabular}

f. Judgments of freedom: "Marvin freely chose to have surgery"/"Ellen freely chose to have sex with Frank"/“Johnny freely chose to allow the police officers to enter and search his home."

Our pre-registration states that as a secondary analysis, we will test whether freedom judgments exhibit the same pattern as consent.

\begin{tabular}{|l|l|l|}
\hline \multicolumn{2}{|l|}{$\mid \mathbf{N}=\mathbf{4 5 0}$ (before exclusions) } & $\mathbf{N}=\mathbf{3 6 4}$ (after exclusions) \\
\hline Mean freedom rating in each of 3 conditions \\
\hline Exercises Capacity & $6.32(0.95), n=155^{\mathrm{a}}$ & $6.46(0.68), n=146^{\mathrm{a}}$ \\
\hline Mere Capacity & $6.28(0.85), n=149^{\mathrm{a}}$ & $6.44(0.73), n=91^{\mathrm{a}}$ \\
\hline Lacks Capacity & $4.80(1.63), n=146^{\mathrm{b}}$ & $4.68(1.67), n=127^{\mathrm{b}}$ \\
\hline $\begin{array}{l}\text { Difference between mean freedom ratings in each of } 3 \text { conditions, adjusting for } \\
\text { vignette domain (random factor) }\end{array}$ \\
\hline $\begin{array}{l}\text { Exercises Capacity } \\
\text { vs. Mere Capacity }\end{array}$ & $\begin{array}{l}b=-.04, S E=0.14, t=-0.30, p= \\
.77, \mathrm{CI}[-0.31,0.23]\end{array}$ & $\begin{array}{l}b=-0.05, S E=0.15, t=-0.31, p \\
=.75, \mathrm{CI}[-0.34,0.25]\end{array}$ \\
\hline $\begin{array}{l}\text { Exercises Capacity } \\
\text { vs. Lacks Capacity }\end{array}$ & $\begin{array}{l}b=-1.52, S E=0.14, t=-11.15, \\
p<.001, \mathrm{CI}[-1.79,-1.25]\end{array}$ & $\begin{array}{l}b=1.79, S E=0.14, t=-13.13, p \\
<.001, \mathrm{CI}[-2.05,-1.52]\end{array}$ \\
\hline $\begin{array}{l}\text { Mere Capacity vs. } \\
\text { Lacks Capacity }\end{array}$ & $\begin{array}{l}b=-1.48, S E=0.14, t=-10.75, \\
p<.001, \mathrm{CI}[-1.75,-1.21]\end{array}$ & $\begin{array}{l}b=-1.74, S E=0.15, t=-11.28, \\
p<.001, \mathrm{CI}[-2.04,-1.44]\end{array}$ \\
\hline
\end{tabular}

\section{Study 2 Results, With and Without Exclusions}

Unless noted otherwise, shared superscripts indicate that means do not differ significantly from one another as revealed by fitting a linear mixed model with autonomy condition included as a fixed factor and domain included as a random factor. Significance of fixed effects was assessed via $t$-tests using Satterthwaite's method.

Where an analysis of a dependent variable indicated a significant difference $(p<.05)$ only after exclusions but not before, or vice versa, the analysis is shaded grey.

a. N per condition 


\begin{tabular}{|l|l|l|}
\hline & $\begin{array}{l}\text { Before } \\
\text { exclusions }\end{array}$ & $\begin{array}{l}\text { After } \\
\text { exclusions }\end{array}$ \\
\hline Exercises Capacity & $\mathrm{N}=212$ & $\mathrm{~N}=157$ \\
\hline Mere Capacity & $\mathrm{N}=211$ & $\mathrm{~N}=95$ \\
\hline Lacks Capacity & $\mathrm{N}=212$ & $\mathrm{~N}=132$ \\
\hline $\begin{array}{l}\text { No condition (e.g., } \\
\text { participant did not } \\
\text { complete survey) }\end{array}$ & $\mathrm{N}=4$ & $\mathrm{~N}=\mathbf{3 8 4}$ \\
\hline Total & $\mathrm{N}=\mathbf{6 3 9}$ \\
\hline $\begin{array}{l}\text { Attention check failure rates differ significantly by } \\
\text { condition, } \chi^{2}(2, N=631)=38.32, p<.001 .\end{array}$ \\
\hline
\end{tabular}

b. Manipulation checks

\begin{tabular}{|c|c|c|}
\hline & $\begin{array}{l}N=639 \text { (before exclusions) } \\
\text { Mean (SD) }\end{array}$ & $\begin{array}{l}N=384 \text { (after exclusions) } \\
\text { Mean (SD) }\end{array}$ \\
\hline \multicolumn{3}{|c|}{$\begin{array}{l}\text { "Marvin has the ability to make rational decisions." } \\
\text { Our pre-registration states that Lacks Capacity condition will be lower than the other two } \\
\text { conditions on this measure. }\end{array}$} \\
\hline Exercises Capacity & $6.21(0.98), n=205^{\mathrm{a}}$ & $6.46(0.73), n=157^{\mathrm{a}}$ \\
\hline Mere Capacity & $5.83(1.17), n=206^{\mathrm{b}}$ & $6.09(0.91), n=95^{\mathrm{b}}$ \\
\hline Lacks Capacity & $3.77(1.91), n=212^{c}$ & $2.91(1.58), n=132^{\mathrm{c}}$ \\
\hline \multicolumn{3}{|c|}{$\begin{array}{l}\text { Mean authentic capacity rating in each of } 3 \text { conditions } \\
\text { "Marvin has the ability to be true to himself when making decisions." } \\
\text { Our pre-registration states that Lacks Capacity condition will be lower than the other two } \\
\text { conditions on this measure. }\end{array}$} \\
\hline Exercises Capacity & $6.00(1.09), n=208^{\mathrm{a}}$ & $6.30(0.80), n=157^{\mathrm{a}}$ \\
\hline Mere Capacity & $5.85(1.14), n=208^{\mathrm{a}}$ & $6.03(0.95), n=95^{\mathrm{a}}$ \\
\hline Lacks Capacity & $4.02(1.73), n=212^{\mathrm{b}}$ & $3.29(1.56), n=132^{\mathrm{b}}$ \\
\hline \multicolumn{3}{|c|}{$\begin{array}{l}\text { Mean general autonomous capacity rating in each of } 3 \text { conditions } \\
\text { "Marvin has the ability to shape his own life freely according to his own values and what is } \\
\text { right for him." } \\
\text { Our pre-registration states that Lacks Capacity condition will be lower than the other two } \\
\text { conditions on this measure. }\end{array}$} \\
\hline Exercises Capacity & $6.16(1.07), n=207^{\mathrm{a}}$ & $6.47(0.71), n=157^{\mathrm{a}}$ \\
\hline Mere Capacity & $5.97(0.95), n=207^{\mathrm{a}}$ & $6.06(0.88), n=95^{\mathrm{b}}$ \\
\hline Lacks Capacity & $4.16(1.79), n=212^{\mathrm{b}}$ & $3.45(1.65), n=132^{\mathrm{c}}$ \\
\hline \multicolumn{3}{|c|}{ Mean rational exercise rating in each of 3 conditions } \\
\hline
\end{tabular}


"Marvin made this particular decision rationally."

Our pre-registration states that Exercises Capacity condition will be higher than the other two conditions on this measure.

\begin{tabular}{|l|l|l|}
\hline Exercises Capacity & $6.09(1.16), n=208^{\mathrm{a}}$ & $6.41(0.85), n=156^{\mathrm{a}}$ \\
\hline Mere Capacity & $3.91(1.94), n=207^{\mathrm{b}}$ & $2.92(1.60), n=95^{\mathrm{b}}$ \\
\hline Lacks Capacity & $3.43(2.03), n=212^{\mathrm{c}}$ & $2.39(1.50), n=132^{\mathrm{c}}$ \\
\hline
\end{tabular}

Mean authentic exercise rating in each of 3 conditions

"When Marvin said 'yes' to having surgery, he was not being true to himself." (reversescored)

Our pre-registration states that Exercises Capacity condition will be higher than the other two conditions on this measure (once it is reverse-scored).

\begin{tabular}{|l|l|l|}
\hline Exercises Capacity & $5.04(2.00), n=209^{\mathrm{a}}$ & $5.69(1.66), n=157^{\mathrm{a}}$ \\
\hline Mere Capacity & $2.89(1.56), n=207^{\mathrm{b}}$ & $3.11(1.61), n=95^{\mathrm{b}}$ \\
\hline Lacks Capacity & $2.97(1.51), n=212^{\mathrm{b}}$ & $3.05(1.60), n=132^{\mathrm{b}}$ \\
\hline
\end{tabular}

\section{Mean general autonomous exercise rating in each of 3 conditions}

"The way Marvin made this particular decision expressed an ability to shape his life freely according to his own values and what is right for him."

Our pre-registration states that Exercises Capacity condition will be higher than the other two conditions on this measure.

\begin{tabular}{|l|l|l|}
\hline Exercises Capacity & $6.08(1.05), n=209^{\mathrm{a}}$ & $6.32(0.82), n=157^{\mathrm{a}}$ \\
\hline Mere Capacity & $4.85(1.70), n=207^{\mathrm{b}}$ & $4.43(1.80), n=95^{\mathrm{b}}$ \\
\hline Lacks Capacity & $4.00(1.90), n=212^{\mathrm{c}}$ & $3.19(1.76), n=132^{\mathrm{c}}$ \\
\hline
\end{tabular}

c. Judgments of valid consent (composite measure)

Our preregistration states that we expected consent judgments to be higher in Mere Capacity than Lacks Capacity, and to find no significant difference between Exercises Capacity and Mere Capacity.

\begin{tabular}{|l|l|l|}
\hline & \multicolumn{1}{|c|}{$\mathbf{N}=\mathbf{6 3 9}$ (before exclusions) } & \multicolumn{1}{|c|}{$\mathbf{N}=\mathbf{3 8 4}$ (after exclusions) } \\
\hline $\begin{array}{l}\text { Cronbach's alpha for } \\
\text { three consent items }\end{array}$ & 0.75 & 0.73 \\
\hline Mean rating of valid consent (composite measure) in each of 3 conditions \\
\hline Exercises Capacity & $5.67(1.49), n=210^{\mathrm{a}}$ & $6.15(1.23), n=157^{\mathrm{a}}$ \\
\hline Mere Capacity & $5.18(1.55), n=207^{\mathrm{b}}$ & $5.93(1.17), n=95^{\mathrm{a}}$ \\
\hline $\begin{array}{l}\text { Lacks Capacity } \\
\text { Difference between mean consent ratings in each of 3 conditions, adjusting for failure } \\
\text { type (random factor) }\end{array}$ & \begin{tabular}{l}
$5.21(1.28), n=132^{\mathrm{b}}$ \\
\hline $\begin{array}{l}\text { Exercises Capacity vs. } \\
\text { Mere Capacity }\end{array}$
\end{tabular}$\quad \begin{array}{l}b=-0.49, S E=0.14, t=-3.41, \\
p<.001, \mathrm{CI}[-0.77,-0.21]\end{array}$ & $\begin{array}{l}b=-0.22, S E=0.16, t=-1.38, \\
p=.167, \mathrm{CI}[-0.54,-0.09]\end{array}$ \\
\hline
\end{tabular}




\begin{tabular}{|l|l|l|}
\hline Exercises Capacity vs. & $\begin{array}{l}b=-0.93, S E=0.14, t=-6.48, \\
\text { Lacks Capacity }\end{array}$ & $\begin{array}{l}b=-0.94, S E=0.15, t=-6.42, \\
p<.001, \text { CI }[-1.22,-0.65]\end{array}$ \\
\hline Mere Capacity vs. & $b=-0.44, S E=0.14, t=-3.04$, & $b=-0.71 S E=0.17, t=-4.30, p$ \\
Lacks Capacity & $p=.002$, CI $[-0.72,-0.15]$ & $<.001$, CI $[-1.04,-0.39]$ \\
\hline
\end{tabular}

d. Judgments of morality: "Under these circumstances, it would be morally wrong for the doctor to proceed with the surgery."

Our pre-registration states that as a secondary analysis, we will test whether morality judgments exhibit the same pattern as consent.

\begin{tabular}{|c|c|c|}
\hline & $\mathrm{N}=639$ (before exclusions) & $\mathrm{N}=384$ (after exclusions) \\
\hline \multicolumn{3}{|c|}{ Mean morality rating in each of 3 conditions } \\
\hline Exercises Capacity & $5.38(2.00), n=208^{\mathrm{a}}$ & $6.06(1.58), n=157^{\mathrm{a}}$ \\
\hline Mere Capacity & $4.38(2.03), n=208^{b}$ & $5.27(1.67), n=95^{\mathrm{b}}$ \\
\hline Lacks Capacity & $3.67(1.79), n=212^{c}$ & $4.02(1.75), n=132^{c}$ \\
\hline \multicolumn{3}{|c|}{$\begin{array}{l}\text { Difference between mean morality ratings in each of } 3 \text { conditions, adjusting for } \\
\text { failure type (random factor) }\end{array}$} \\
\hline $\begin{array}{l}\text { Exercises Capacity } \\
\text { vs. Mere Capacity }\end{array}$ & $\begin{array}{l}b=-0.99, S E=0.19, t=-5.22, p \\
<.001, \text { CI }[-1.36,-0.62]\end{array}$ & $\begin{array}{l}b=-0.77, S E=0.21, t=-3.56, p \\
<.001, \text { CI }[-1.19,-0.34]\end{array}$ \\
\hline $\begin{array}{l}\text { Exercises Capacity } \\
\text { vs. Lacks Capacity }\end{array}$ & $\begin{array}{l}b=-1.70, S E=0.19, t=-9.01, p \\
<.001, \text { CI }[-2.07,-1.33]\end{array}$ & $\begin{array}{l}b=-2.02, S E=0.20, t=-10.34 \\
p<.001, \mathrm{CI}[-2.40,-1.64]\end{array}$ \\
\hline $\begin{array}{l}\text { Mere Capacity vs. } \\
\text { Lacks Capacity }\end{array}$ & $\begin{array}{l}b=-0.71, S E=0.19, t=-3.76, p \\
<.001, \text { CI }[-1.08,-0.34]\end{array}$ & $\begin{array}{l}b=-1.26, S E=0.22, t=-5.64, p \\
<.001, \text { CI }[-1.69,-0.82]\end{array}$ \\
\hline
\end{tabular}

e. Judgments of freedom: "Marvin freely chose to have surgery."

Our pre-registration states that as a secondary analysis, we will test whether freedom judgments exhibit the same pattern as consent.

\begin{tabular}{|c|c|c|}
\hline & $N=639$ (before exclusions) & $\mathrm{N}=384$ (after exclusions) \\
\hline \multicolumn{3}{|c|}{ Mean freedom rating in each of 3 conditions } \\
\hline Exercises Capacity & $6.20(1.18), n=208^{\mathrm{a}}$ & $6.53(0.84), n=157^{\mathrm{a}}$ \\
\hline Mere Capacity & $5.74(1.21), n=207^{\mathrm{b}}$ & $5.87(1.31), n=95^{\mathrm{a}}$ \\
\hline Lacks Capacity & $4.92(1.67), n=212^{c}$ & $4.67(1.75), n=132^{b}$ \\
\hline \multicolumn{3}{|c|}{$\begin{array}{l}\text { Difference between mean freedom ratings in each of } 3 \text { conditions, adjusting for } \\
\text { failure type (random factor) }\end{array}$} \\
\hline $\begin{array}{l}\text { Exercises Capacity } \\
\text { vs. Mere Capacity }\end{array}$ & $\begin{array}{l}b=-0.45, S E=0.13, t=-3.45, p \\
<.001, \text { CI }[-0.71,-0.20]\end{array}$ & $\begin{array}{l}b=-0.69, S E=0.16, t=-4.22, p \\
<.001, \text { CI }[-1.01,-0.37]\end{array}$ \\
\hline $\begin{array}{l}\text { Exercises Capacity } \\
\text { vs. Lacks Capacity }\end{array}$ & $\begin{array}{l}b=-1.28, S E=0.13, t=-9.85, p \\
<.001, \text { CI }[-1.54,-1.03]\end{array}$ & $\begin{array}{l}b=-1.88, S E=0.15, t=-12.70 \\
p<.001, \mathrm{CI}[-2.18,-1.59]\end{array}$ \\
\hline
\end{tabular}




\begin{tabular}{|l|l|l|}
\hline Mere Capacity vs. & $b=-0.83, S E=0.13, t=-6.37, p$ & $b=-1.19, S E=0.17, t=-7.08, p$ \\
Lacks Capacity & $<.001$, CI $[-1.09,-0.58]$ & $<.001$, CI $[-1.53,-0.87]$
\end{tabular}

\section{Study 3 results with and without exclusions}

Unless noted otherwise, shared superscripts indicate that means do not differ significantly from one another as revealed by fitting a linear model with autonomy condition as a fixed factor. Significance of fixed effects was assessed via $t$-tests using Satterthwaite's method.

Where an analysis of a dependent variable indicated a significant difference $(p<.05)$ only after exclusions but not before, or vice versa, the analysis is shaded grey.

a. N per condition

\begin{tabular}{|l|l|l|}
\hline & $\begin{array}{l}\text { Before } \\
\text { exclusions }\end{array}$ & $\begin{array}{l}\text { After } \\
\text { exclusions }\end{array}$ \\
\hline Exercises Capacity & $\mathrm{N}=101$ & $\mathrm{~N}=43$ \\
\hline Mere Capacity & $\mathrm{N}=100$ & $\mathrm{~N}=49$ \\
\hline Lacks Capacity & $\mathrm{N}=102$ & $\mathrm{~N}=61$ \\
\hline Total & $\mathbf{N}=\mathbf{3 0 3}$ & $\mathbf{N}=\mathbf{1 5 3}$ \\
\hline
\end{tabular}

Attention check failure rates differ significantly by condition, $\chi^{2}(2, N=303)=11.35, p=.003$.

b. Manipulation checks

\begin{tabular}{|c|c|c|}
\hline & $\begin{array}{l}\mathrm{N}=303 \text { (before exclusions) } \\
\text { Mean (SD) }\end{array}$ & $\begin{array}{l}N=153 \text { (after exclusions) } \\
\text { Mean (SD) }\end{array}$ \\
\hline \multicolumn{3}{|c|}{$\begin{array}{l}\text { Mean rational capacity rating in each of } 3 \text { conditions } \\
\text { "When Sam asked whether he could sell the bracelet, Jessica had the ability to make a } \\
\text { rational decision." }\end{array}$} \\
\hline Exercises Capacity & $5.58(1.25), n=101^{\mathrm{a}}$ & $5.88(1.12), n=43^{\mathrm{a}}$ \\
\hline Mere Capacity & $5.02(1.56), n=100^{\mathrm{b}}$ & $4.96(1.73), n=49^{\mathrm{b}}$ \\
\hline Lacks Capacity & $3.49(2.28), n=102^{\mathrm{c}}$ & $2.11(1.60), n=61^{\mathrm{c}}$ \\
\hline \multicolumn{3}{|c|}{$\begin{array}{l}\text { Mean authentic capacity rating in each of } 3 \text { conditions } \\
\text { "Jessica had the ability to be true to herself when making a decision about whether to le } \\
\text { Sam sell the bracelet." }\end{array}$} \\
\hline Exercises Capacity & $5.49(1.30), n=101^{\mathrm{a}}$ & $5.74(1.18), n=43^{\mathrm{a}}$ \\
\hline Mere Capacity & $5.02(1.64), n=100^{\mathrm{a}}$ & $4.80(1.86), n=49^{b}$ \\
\hline Lacks Capacity & $3.63(2.27), n=102^{\mathrm{b}}$ & $2.25(1.70), n=61^{\mathrm{c}}$ \\
\hline
\end{tabular}




\begin{tabular}{|c|c|c|}
\hline \multicolumn{3}{|c|}{ "Jessica made the decision to say 'yes' rationally." } \\
\hline Exercises Capacity & $5.34(1.45), n=101^{\mathrm{a}}$ & $5.84(1.17), n=43^{\mathrm{a}}$ \\
\hline Mere Capacity & $4.48(1.75), n=100^{\mathrm{b}}$ & $3.88(1.79), n=49^{\mathrm{b}}$ \\
\hline Lacks Capacity & $3.77(2.32), n=102^{\mathrm{c}}$ & $2.41(1.85), n=61^{\mathrm{c}}$ \\
\hline \multicolumn{3}{|c|}{$\begin{array}{l}\text { Mean authentic exercise rating in each of } 3 \text { conditions } \\
\text { "'When Jessica said 'yes' to Sam's selling the bracelet, she was not being true to herself.' } \\
\text { (reverse-scored) }\end{array}$} \\
\hline Exercises Capacity & $3.65(1.79), n=101^{\mathrm{a}}$ & $4.86(1.68), n=43^{\mathrm{a}}$ \\
\hline Mere Capacity & $2.84(1.33), n=100^{\mathrm{b}}$ & $3.12(1.49), n=49^{\mathrm{b}}$ \\
\hline Lacks Capacity & $2.11(1.07), n=102^{\mathrm{c}}$ & $1.93(0.98), n=61^{\mathrm{c}}$ \\
\hline
\end{tabular}

c. Judgments of valid consent

Our pre-registration predicted that the Lacks Capacity condition will yield lower consent ratings than the Mere Capacity condition.

\begin{tabular}{|c|c|c|}
\hline & $\begin{array}{l}\text { N = } 303 \text { (before exclusions) } \\
\text { Mean (SD) }\end{array}$ & $\begin{array}{l}N=153 \text { (after exclusions) } \\
\text { Mean (SD) }\end{array}$ \\
\hline $\begin{array}{l}\text { Cronbach's alpha } \\
\text { for three consent } \\
\text { items }\end{array}$ & 0.76 & 0.89 \\
\hline \multicolumn{3}{|c|}{ Mean rating of valid consent (composite measure) in each of 3 conditions } \\
\hline Exercises Capacity & $4.60(1.51), n=101^{\mathrm{a}}$ & $5.84(1.27), n=43^{\mathrm{a}}$ \\
\hline Mere Capacity & $4.25(1.34), n=100^{\mathrm{a}}$ & $4.80(1.56), n=49^{\mathrm{b}}$ \\
\hline Lacks Capacity & $3.02(1.27), n=102^{b}$ & $2.75(1.53), n=61^{\mathrm{c}}$ \\
\hline \multicolumn{3}{|c|}{ Omnibus F Test examining whether mean consent ratings differ by condition } \\
\hline & $F(2,300)=37.29, p<.001$ & $F(2,150)=59.82, p<.001$ \\
\hline \multicolumn{3}{|c|}{ Difference between mean consent ratings in each of 3 conditions } \\
\hline $\begin{array}{l}\text { Exercises Capacity } \\
\text { vs. Mere Capacity }\end{array}$ & $\begin{array}{l}b=0.34, S E=0.19, t=1.82, p= \\
.069, \text { CI }[-0.74,-0.03]\end{array}$ & $\begin{array}{l}b=1.03, S E=0.31, t=3.36, p= \\
.001, \text { CI }[-1.64,-0.43]\end{array}$ \\
\hline $\begin{array}{l}\text { Exercises Capacity } \\
\text { vs. Lacks Capacity }\end{array}$ & $\begin{array}{l}b=1.59, S E=0.19, t=8.22, p< \\
.001, \text { CI }[-1.97,-1.21]\end{array}$ & $\begin{array}{l}b=3.08, S E=0.29, t=10.51, p \\
<.001, \text { CI }[-3.66,-2.50]\end{array}$ \\
\hline $\begin{array}{l}\text { Mere Capacity vs. } \\
\text { Lacks Capacity }\end{array}$ & $\begin{array}{l}b=1.23, S E=0.19, t=6.37, p< \\
.001, \text { CI }[-1.61,-0.85]\end{array}$ & $\begin{array}{l}b=2.05, S E=0.28, t=7.25, p< \\
.001, \text { CI }[-2.61,-1.49]\end{array}$ \\
\hline
\end{tabular}

d. Judgments of (1) ownership transfer: composite continuous measure and (2) binary ownership measure ("Who is the rightful owner of the bracelet?" Jessica/Melanie) 
For the continuous measure, our pre-registration states that we predict the Lacks Capacity condition will yield lower ratings of ownership transfer than the Mere Capacity condition. For the binary measure, the pre-registration states that we will conduct Fisher's exact tests analyzing whether the percentage of participants answering "Melanie" differs between the autonomy conditions. We predicted lower rates in the Lacks Capacity condition.

\begin{tabular}{|c|c|c|}
\hline & $\begin{array}{l}\mathbf{N}=303 \text { (before exclusions) } \\
\text { Mean (SD) }\end{array}$ & $\begin{array}{l}N=153 \text { (after exclusions) } \\
\text { Mean (SD) }\end{array}$ \\
\hline $\begin{array}{l}\text { Cronbach's alpha } \\
\text { for five ownership } \\
\text { items }\end{array}$ & 0.91 & 0.91 \\
\hline \multicolumn{3}{|c|}{$\begin{array}{l}\text { Mean rating of ownership transfer (composite continuous measure) in each of } 3 \\
\text { conditions }\end{array}$} \\
\hline Exercises Capacity & $4.29(1.54), n=101^{\mathrm{a}}$ & $5.53(1.36), n=43^{\mathrm{a}}$ \\
\hline Mere Capacity & $4.00(1.44), n=100^{\mathrm{a}}$ & $4.71(1.58), n=49^{\mathrm{b}}$ \\
\hline Lacks Capacity & $3.11(1.14), n=102^{b}$ & $3.18(1.40), n=61^{\mathrm{c}}$ \\
\hline \multicolumn{3}{|c|}{$\begin{array}{l}\text { Omnibus F Test examining whether mean ownership transfer ratings differ by } \\
\text { condition }\end{array}$} \\
\hline & $F(2,300)=19.90, p<.001$ & $F(2,150)=35.60, p<.001$ \\
\hline \multicolumn{3}{|c|}{ Difference between mean ownership transfer ratings in each of 3 conditions } \\
\hline $\begin{array}{l}\text { Exercises Capacity } \\
\text { vs. Mere Capacity }\end{array}$ & $\begin{array}{l}b=0.29 S E=0.20, t=1.46, p= \\
.15, \text { CI }[-0.67,0.10]\end{array}$ & $\begin{array}{l}b=0.82, S E=0.31, t=2.69, p= \\
.008, \mathrm{CI}[-1.41,-0.22]\end{array}$ \\
\hline $\begin{array}{l}\text { Exercises Capacity } \\
\text { vs. Lacks Capacity }\end{array}$ & $\begin{array}{l}b=1.18, S E=0.19, t=6.05, p< \\
.001, \mathrm{CI}[-1.56,-0.79]\end{array}$ & $\begin{array}{l}b=2.35, S E=0.29, t=8.14, p< \\
.001, \text { CI }[-2.92,-1.78]\end{array}$ \\
\hline $\begin{array}{l}\text { Mere Capacity vs. } \\
\text { Lacks Capacity }\end{array}$ & $\begin{array}{l}b=0.98, S E=0.20, t=4.57, p< \\
.001, \mathrm{CI}[-1.27,-0.51]\end{array}$ & $\begin{array}{l}b=1.53, S E=0.28, t=5.51, p< \\
.001, \text { CI }[-2.08,-0.98]\end{array}$ \\
\hline \multicolumn{3}{|c|}{$\begin{array}{l}\text { Percentage concluding that ownership transferred to the recipient Melanie (binary } \\
\text { measure) in each of } 3 \text { conditions }\end{array}$} \\
\hline Exercises Capacity & $46.53 \%, n=101^{\mathrm{a}}$ & $81.40 \%, n=43^{\mathrm{a}}$ \\
\hline Mere Capacity & $40.00 \%, n=100^{\mathrm{a}}$ & $57.14 \%, n=49^{\mathrm{b}}$ \\
\hline Lacks Capacity & $20.59 \%, n=102^{\mathrm{b}}$ & $21.31 \%, n=61^{\mathrm{c}}$ \\
\hline \multicolumn{3}{|c|}{$\begin{array}{l}\text { Fisher's exact tests comparing rates at which participants concluded ownership had } \\
\text { transferred to Melanie across conditions. } \\
\text { We report chi-square test statistics as well. }\end{array}$} \\
\hline $\begin{array}{l}\text { Exercises Capacity } \\
\text { vs. Mere Capacity }\end{array}$ & $\begin{array}{l}\mathrm{OR}=0.77, p=.39, \mathrm{CI}[.42 \\
1.39] \\
X^{2}(1)=.628, p=.43\end{array}$ & $\begin{array}{l}\mathrm{OR}=0.31, p=.014, \mathrm{CI}[0.10 \\
0.86] \\
X^{2}(1)=5.17, p=.023\end{array}$ \\
\hline $\begin{array}{l}\text { Exercises Capacity } \\
\text { vs. Lacks Capacity }\end{array}$ & $\begin{array}{l}\mathrm{OR}=0.30, p<.001, \mathrm{CI}[0.15 \\
0.58] ; X^{2}(1)=14.19, p<.001\end{array}$ & $\begin{array}{l}\mathrm{OR}=0.06, p<.001, \mathrm{CI}[0.02 \\
0.18] ; X^{2}(1)=34.26, p<.001\end{array}$ \\
\hline
\end{tabular}


Mere Capacity vs. Lacks Capacity

$$
\begin{aligned}
& \mathrm{OR}=0.39, p=.003, \mathrm{CI}[0.19 \\
& 0.76] ; X^{2}(1)=8.13, p=.004
\end{aligned}
$$

$\mathrm{OR}=0.21, p<.001, \mathrm{CI}[0.08$ $0.50] ; X^{2}(1)=13.43, p<.001$

Linear regression predicting ownership transfer judgments from consent judgments, adjusting for condition. The relationship between ownership transfer and consent judgments varied by condition; thus we interact consent and condition.

\begin{tabular}{|l|l|}
$b=-0.83, S E=.07, t=-11.68, p$ & $b=-0.80, S E=.10, t=-8.16, p<$ \\
$<.001$, CI [-0.97, -0.69] & .001, CI [-0.99, -0.61]
\end{tabular}

e. Judgments of morality: "Under these circumstances, it was morally wrong for Sam to proceed with selling the bracelet." (reverse-scored)

Our pre-registration stated that as a secondary analysis we would examine the effect of

\begin{tabular}{|c|c|c|}
\hline & $\begin{array}{l}\mathbf{N}=303 \text { (before exclusions) } \\
\text { Mean (SD) }\end{array}$ & $\begin{array}{l}N=153 \text { (after exclusions) } \\
\text { Mean (SD) }\end{array}$ \\
\hline \multicolumn{3}{|c|}{ Mean morality rating in each of 3 conditions } \\
\hline Exercises Capacity & $3.16(1.82), n=101^{\mathrm{a}}$ & $4.14(2.01), n=43^{\mathrm{a}}$ \\
\hline Mere Capacity & $2.44(1.47), n=100^{b}$ & $2.43(1.62), n=49^{\mathrm{b}}$ \\
\hline Lacks Capacity & $1.84(0.96), n=102^{\mathrm{c}}$ & $1.61(0.94), n=61^{\mathrm{c}}$ \\
\hline \multicolumn{3}{|c|}{ Omnibus F Test examining whether mean morality ratings differ by condition } \\
\hline & $F(2,300)=20.71, p<.001$ & $F(2,150)=35.27, p<.001$ \\
\hline \multicolumn{3}{|c|}{ Difference between mean morality ratings in each of 3 conditions } \\
\hline $\begin{array}{l}\text { Exercises Capacity } \\
\text { vs. Mere Capacity }\end{array}$ & $\begin{array}{l}b=-0.72, S E=0.21, t=-3.49, p \\
<.001, \text { CI }[-1.12,-0.31]\end{array}$ & $\begin{array}{l}b=-1.71, S E=0.32, t=-5.38, p \\
<.001, \text { CI }[-2.34,-1.08]\end{array}$ \\
\hline $\begin{array}{l}\text { Exercises Capacity } \\
\text { vs. Lacks Capacity }\end{array}$ & $\begin{array}{l}b=-1.32, S E=0.20, t=-6.43, p \\
<.001, \text { CI }[-1.72,-0.91]\end{array}$ & $\begin{array}{l}b=-2.53, S E=0.30, t=-8.36, p \\
<.001, \text { CI }[-3.13,-1.93]\end{array}$ \\
\hline $\begin{array}{l}\text { Mere Capacity vs. } \\
\text { Lacks Capacity }\end{array}$ & $\begin{array}{l}b=-0.60, S E=0.21, t=-2.91, p \\
=.003, \text { CI }[-1.00,-0.19]\end{array}$ & $\begin{array}{l}b=-0.82, S E=0.29, t=-2.81, p \\
=.006, \text { CI }[-1.40,-0.24]\end{array}$ \\
\hline
\end{tabular}
condition on morality judgments.

f. Judgments of right choice: "Saying 'yes' to selling the bracelet was probably the right choice for Jessica at the time."

Our pre-registration stated that as a secondary analysis we would examine the effect of condition on judgments of right choice. 


\begin{tabular}{|c|c|c|}
\hline \multicolumn{3}{|c|}{ Mean right choice rating in each of 3 conditions } \\
\hline Exercises Capacity & $4.71(1.63), n=101^{\mathrm{a}}$ & $4.23(1.66), n=43^{\mathrm{a}}$ \\
\hline Mere Capacity & $3.95(1.84), n=100^{\mathrm{b}}$ & $3.20(1.68), n=49^{\mathrm{b}}$ \\
\hline Lacks Capacity & $3.79(2.28), n=102^{\mathrm{b}}$ & $2.39(1.76), n=61^{\mathrm{c}}$ \\
\hline \multicolumn{3}{|c|}{ Difference between mean right choice ratings in each of 3 conditions } \\
\hline $\begin{array}{l}\text { Exercises Capacity } \\
\text { vs. Mere Capacity }\end{array}$ & $\begin{array}{l}b=-0.76, S E=0.27, t=-2.79, p \\
=.006, \mathrm{CI}[-1.30,-0.22]\end{array}$ & $\begin{array}{l}b=-1.03, S E=0.36, t=-2.88, p \\
=.004, \text { CI }[-1.73,-0.32]\end{array}$ \\
\hline $\begin{array}{l}\text { Exercises Capacity } \\
\text { vs. Lacks Capacity }\end{array}$ & $\begin{array}{l}b=-0.92, S E=0.27, t=-3.38, p \\
<.001, \text { CI }[-1.45,-0.38]\end{array}$ & $\begin{array}{l}b=-1.84, S E=0.34, t=-5.40, p \\
<.001, \text { CI }[-2.51,-1.17]\end{array}$ \\
\hline $\begin{array}{l}\text { Mere Capacity vs. } \\
\text { Lacks Capacity }\end{array}$ & $\begin{array}{l}b=-0.16, S E=0.27, t=-0.57, p \\
=.57, \mathrm{CI}[-0.69,-0.38]\end{array}$ & $\begin{array}{l}b=-0.81, S E=0.33, t=-2.47, p \\
=.015, \text { CI }[-1.46,-0.16]\end{array}$ \\
\hline
\end{tabular}

g. Judgments of freedom: "Jessica freely chose to sell her bracelet."

Our pre-registration stated that as a secondary analysis we would examine the effect of condition on freedom judgments.

\begin{tabular}{|c|c|c|}
\hline & $\begin{array}{l}\mathrm{N}=303 \text { (before exclusions) } \\
\text { Mean (SD) }\end{array}$ & $\begin{array}{l}N=153 \text { (after exclusions) } \\
\text { Mean (SD) }\end{array}$ \\
\hline \multicolumn{3}{|c|}{ Mean freedom rating in each of 3 conditions } \\
\hline Exercises Capacity & $5.15(1.53), n=101^{\mathrm{a}}$ & $5.58(1.42), \mathrm{n}=43^{\mathrm{a}}$ \\
\hline Mere Capacity & $4.79(1.74), n=100^{\mathrm{a}}$ & $4.67(1.84), \mathrm{n}=49^{\mathrm{b}}$ \\
\hline Lacks Capacity & $3.69(2.37), n=102^{\mathrm{b}}$ & $2.30(1.74), \mathrm{n}=61^{\mathrm{c}}$ \\
\hline \multicolumn{3}{|c|}{ Difference between mean freedom ratings in each of 3 conditions } \\
\hline $\begin{array}{l}\text { Exercises Capacity } \\
\text { vs. Mere Capacity }\end{array}$ & $\begin{array}{l}B=-0.36, S E=0.27, t=-1.33, p \\
=.19, \text { CI }[-0.89,-0.17]\end{array}$ & $\begin{array}{l}b=-0.91, S E=0.35, t=-2.57, p \\
=.011, \text { CI }[-1.61,-0.21]\end{array}$ \\
\hline $\begin{array}{l}\text { Exercises Capacity } \\
\text { vs. Lacks Capacity }\end{array}$ & $\begin{array}{l}b=-1.46, S E=0.27, t=-5.44, p \\
<.001, \text { CI }[-1.99,-0.93]\end{array}$ & $\begin{array}{l}b=-3.29, S E=0.34, t=-9.77, p \\
<.001, \text { CI }[-3.95,-2.62]\end{array}$ \\
\hline $\begin{array}{l}\text { Mere Capacity vs. } \\
\text { Lacks Capacity }\end{array}$ & $\begin{array}{l}b=-1.10, S E=0.27, t=-4.09, p \\
<.001, \text { CI }[-1.63,-0.57]\end{array}$ & $\begin{array}{l}b=-2.38, S E=0.32, t=-7.34, p \\
<.001, \text { CI }[-3.02,-1.74]\end{array}$ \\
\hline
\end{tabular}

\section{Appendix B: Stimuli}

1. STUDY 1 STIMULI

a. Study 1 vignettes by condition

MEDICAL 
Marvin has been in physical therapy for ankle pain. One day his doctor asks him whether he wishes to undergo elective surgery to repair the tendon. The doctor explains that the surgery carries some risks, as all surgeries do, but if all goes well it could potentially completely cure his ankle pain.

\begin{tabular}{|l|l|l|}
\hline Exercises Capacity & Mere Capacity & Lacks Capacity \\
\hline $\begin{array}{l}\text { Marvin is an intelligent, able } \\
\text { adult. He is perfectly capable } \\
\text { of weighing up pros and cons; } \\
\text { thinking through the choice he } \\
\text { faces; and making decisions } \\
\text { based on what is best for him, } \\
\text { which options align with his } \\
\text { personal values, and what he } \\
\text { really wants. }\end{array}$ & $\begin{array}{l}\text { Marvin is an intelligent, able } \\
\text { adult. He is perfectly capable } \\
\text { thinking through the choice he } \\
\text { faces; and making decisions } \\
\text { based on what is best for him, } \\
\text { which options align with his } \\
\text { personal values, and what he } \\
\text { really wants. }\end{array}$ & $\begin{array}{l}\text { Marvin is not able and } \\
\text { intelligent like most adults. He } \\
\text { is completely incapable of } \\
\text { weighing up pros and cons; } \\
\text { thinking through the choice he } \\
\text { faces; or making decisions } \\
\text { based on what is best for him, } \\
\text { which options align with his } \\
\text { personal values, or what he } \\
\text { really wants. }\end{array}$ \\
$\begin{array}{l}\text { After thinking things through } \\
\text { very carefully--and with } \\
\text { careful regard for the pros and } \\
\text { cons, and whether it aligns with } \\
\text { his personal values and what he } \\
\text { really wants--Marvin says 'yes' } \\
\text { to the surgery. }\end{array}$ & $\begin{array}{l}\text { But he does not do so in this } \\
\text { instance. Without thinking } \\
\text { things through even a little bit-- } \\
\text { and with absolutely no regard } \\
\text { for the pros and cons, or } \\
\text { whether it aligns with his } \\
\text { personal values and what he } \\
\text { really wants--Marvin says 'yes' } \\
\text { to the surgery. }\end{array}$ & $\begin{array}{l}\text { So he does not do so in this } \\
\text { instance. Without thinking } \\
\text { things through even a little bit-- } \\
\text { and with absolutely no regard } \\
\text { for the pros and cons, or } \\
\text { whether it aligns with his } \\
\text { personal values and what he } \\
\text { really wants--Marvin says 'yes' } \\
\text { to the surgery. }\end{array}$ \\
\hline
\end{tabular}

\section{SEXUAL}

Ellen and Frank meet in a night class. They go on several dates. At the end of their last date, Frank asks Ellen to have sex with him. He adds, "I know we haven't known each other very long, but I've been enjoying our time together, and this feels right to me."

\begin{tabular}{|l|l|l|}
\hline Exercises Capacity & Mere Capacity & Lacks Capacity \\
\hline $\begin{array}{l}\text { Ellen is an intelligent, able } \\
\text { adult. She is perfectly capable } \\
\text { of weighing up pros and cons; } \\
\text { thinking through the choice she } \\
\text { faces; and making decisions } \\
\text { based on what is best for her, } \\
\text { which options align with her } \\
\text { personal values, and what she } \\
\text { really wants. }\end{array}$ & $\begin{array}{l}\text { Ellen is an intelligent, able } \\
\text { adult. She is perfectly capable } \\
\text { thinking through the choice she } \\
\text { faces; and making decisions } \\
\text { based on what is best for her, } \\
\text { which options align with her } \\
\text { personal values, and what she } \\
\text { really wants. }\end{array}$ & $\begin{array}{l}\text { Ellen is not able and intelligent } \\
\text { like most adults. She is } \\
\text { completely incapable of } \\
\text { weighing up pros and cons; } \\
\text { thinking through the choice she } \\
\text { faces; or making decisions } \\
\text { based on what is best for her, } \\
\text { which options align with her } \\
\text { personal values, or what she } \\
\text { really wants. }\end{array}$ \\
$\begin{array}{l}\text { And she does so in this } \\
\text { instance. After thinking things } \\
\text { through very carefully--and } \\
\text { with careful regard for the pros } \\
\text { and cons, and whether it aligns } \\
\text { with her personal values and } \\
\text { what she really wants--Ellen }\end{array}$ & $\begin{array}{l}\text { But she does not do so in this } \\
\text { instance. Without thinking } \\
\text { things through even a little bit-- } \\
\text { and with absolutely no regard } \\
\text { for the pros and cons, or } \\
\text { whether it aligns with her } \\
\text { personal values and what she }\end{array}$ & $\begin{array}{l}\text { So she does not do so in this } \\
\text { instance. Without thinking } \\
\text { things through even a little bit-- } \\
\text { and with absolutely no regard } \\
\text { for the pros and cons, or } \\
\text { whether it aligns with her } \\
\text { personal values and what she }\end{array}$ \\
\hline
\end{tabular}


says 'yes' to having sex with Frank. really wants--Ellen says 'yes' to having sex with Frank. really wants--Ellen says 'yes' to having sex with Frank.

\begin{tabular}{|c|c|c|}
\hline \multicolumn{3}{|c|}{ POLICE ENTRY } \\
\hline \multicolumn{3}{|c|}{$\begin{array}{l}\text { Johnny hears someone knock on his apartment door. Two men are standing outside. They say, } \\
\text { "Police here. Can we come in?" Johnny asks through the door, "What for?" One of the police } \\
\text { officers says, "We are looking for drugs and drug paraphernalia. We got an anonymous call } \\
\text { reporting drug dealing in this building. So can we come in?" }\end{array}$} \\
\hline Exercises Capacity & Mere Capacity & Lacks Capacity \\
\hline $\begin{array}{l}\text { Johnny is an intelligent, able } \\
\text { adult. He is perfectly capable } \\
\text { of weighing up pros and cons; } \\
\text { thinking through the choice he } \\
\text { faces; and making decisions } \\
\text { based on what is best for him, } \\
\text { which options align with his } \\
\text { personal values, and what he } \\
\text { really wants. } \\
\text { And he does so in this instance. } \\
\text { After thinking things through } \\
\text { very carefully--and with } \\
\text { careful regard for the pros and } \\
\text { cons, and whether it aligns with } \\
\text { his personal values and what he } \\
\text { really wants--Johnny says 'yes' } \\
\text { to letting the police search his } \\
\text { apartment. }\end{array}$ & $\begin{array}{l}\text { Johnny is an intelligent, able } \\
\text { adult. He is perfectly capable } \\
\text { of weighing up pros and cons; } \\
\text { thinking through the choice he } \\
\text { faces; and making decisions } \\
\text { based on what is best for him, } \\
\text { which options align with his } \\
\text { personal values, and what he } \\
\text { really wants. } \\
\text { But he does not do so in this } \\
\text { instance. Without thinking } \\
\text { things through even a little bit-- } \\
\text { and with absolutely no regard } \\
\text { for the pros and cons, or } \\
\text { whether it aligns with his } \\
\text { personal values and what he } \\
\text { really wants--Johnny says 'yes' } \\
\text { to letting the police search his } \\
\text { apartment. }\end{array}$ & $\begin{array}{l}\text { Johnny is not able and } \\
\text { intelligent like most adults. He } \\
\text { is completely incapable of } \\
\text { weighing up pros and cons; } \\
\text { thinking through the choice he } \\
\text { faces; or making decisions } \\
\text { based on what is best for him, } \\
\text { which options align with his } \\
\text { personal values, or what he } \\
\text { really wants. } \\
\text { So he does not do so in this } \\
\text { instance. Without thinking } \\
\text { things through even a little bit-- } \\
\text { and with absolutely no regard } \\
\text { for the pros and cons, or } \\
\text { whether it aligns with his } \\
\text { personal values and what he } \\
\text { really wants--Johnny says 'yes' } \\
\text { to letting the police search his } \\
\text { apartment. }\end{array}$ \\
\hline
\end{tabular}

\section{b. Study 1 measures}

" $X$ " and " $Y$ " replaced to refer to the relevant agents and " $z$ " replaced with the relevant action, according to vignette viewed by the participant.

\section{Consent}

Consent 1: X had Y's permission to proceed with $\mathrm{z}$.

Consent 2: If $X$ proceeds with $z$-ing now, he'll be acting without $Y$ 's consent.

Consent 3: Y's 'yes' didn't count as consent.

Morality: Under these circumstances, it would be morally wrong for $\mathrm{Y}$ to proceed with z-ing.

Freedom: Y freely chose to z. 
Right Choice: Z-ing was probably the right choice for X.

\section{Manipulation checks}

Rational capacity: $\mathrm{Y}$ has the ability to make rational decisions.

Rational exercise: Y made this particular decision rationally.

Authentic capacity: $\mathrm{Y}$ has the ability to be true to him[her]self when making decisions.

Authentic exercise: When Y said 'yes' to z-ing, [s] he was not being true to $\operatorname{him}[$ her] $]$ elf.

\section{c. Study 1 attention checks}

Which is correct?

a. $\quad \mathrm{Y}$ did think through the pros and cons of z-ing.

b. $\mathrm{Y}$ did not think through the pros and cons of $\mathrm{z}$-ing.

Y made this particular decision ...

a. with regard for whether $\mathrm{z}$-ing aligned with his[her] personal values.

b. without regard for whether $\mathrm{z}$-ing aligned with his[her] personal values.

At the time $\mathrm{X}$ suggested $\mathrm{z}$-ing, $\mathrm{Y}$ was ...
a. capable of thinking through his[her] choice and deciding based on the pros and cons
b. incapable of thinking through his[her] choice and deciding based on the pros and cons

At the time X suggested z-ing, Y was ...
a. $\quad$ able to make a decision based on which option aligned with his[her] personal values.
b. $\quad$ unable to make a decision based on which option aligned with his[her] personal values.

\section{STUDY 2 STIMULI}

\section{a. Study 2 vignettes by condition}

All vignettes begin:

Please read the following story carefully.

Marvin has been in physical therapy for ankle pain. One day his doctor asks him whether he wishes to undergo elective surgery to repair the tendon. The doctor explains that the surgery carries some risks, as all surgeries do, but if all goes well it could potentially completely cure his ankle pain.

The vignettes continue according to autonomy and failure type condition: 


\begin{tabular}{|c|c|c|}
\hline \multicolumn{3}{|c|}{ IMPULSE } \\
\hline Exercises Capacity & Mere Capacity & Lacks Capacity \\
\hline $\begin{array}{l}\text { Marvin feels an initial impulse } \\
\text { to simply say 'no' surgery. }\end{array}$ & $\begin{array}{l}\text { Marvin feels an initial impulse } \\
\text { to simply say 'yes' to surgery. }\end{array}$ & $\begin{array}{l}\text { Marvin feels an initial impulse } \\
\text { to simply say 'yes' to surgery. }\end{array}$ \\
\hline $\begin{array}{l}\text { Marvin is an intelligent, able } \\
\text { adult, fully capable of making } \\
\text { decisions for himself and } \\
\text { controlling impulses when they } \\
\text { are inappropriate. }\end{array}$ & $\begin{array}{l}\text { Marvin is an intelligent, able } \\
\text { adult, fully capable of making } \\
\text { decisions for himself and } \\
\text { controlling impulses when they } \\
\text { are inappropriate. }\end{array}$ & $\begin{array}{l}\text { Marvin is not able and } \\
\text { intelligent like most adults who } \\
\text { are fully capable of making } \\
\text { decisions for themselves: he is } \\
\text { completely incapable of } \\
\text { controlling impulses, even } \\
\text { when they are inappropriate. }\end{array}$ \\
\hline $\begin{array}{l}\text { And he does so in this instance. } \\
\text { Although he feels an initial } \\
\text { impulse to avoid surgery, he } \\
\text { thinks things through carefully, } \\
\text { and makes his decision with } \\
\text { careful regard for the pros and } \\
\text { cons, and whether surgery } \\
\text { aligns with his personal values } \\
\text { and what he really wants. } \\
\text { Because of this, Marvin says } \\
\text { 'yes' to the surgery. }\end{array}$ & $\begin{array}{l}\text { But he does not do so in this } \\
\text { instance. Acting on an initial } \\
\text { impulse to have the surgery, he } \\
\text { doesn't think things through } \\
\text { even a little bit, and pays } \\
\text { absolutely no attention to the } \\
\text { pros and cons, or whether } \\
\text { surgery aligns with his personal } \\
\text { values and what he really } \\
\text { wants. He simply says 'yes' to } \\
\text { the surgery on an impulse. }\end{array}$ & $\begin{array}{l}\text { So he does not do so in this } \\
\text { instance. Acting on an initial } \\
\text { impulse to have the surgery, he } \\
\text { doesn't think things through } \\
\text { even a little bit, and pays } \\
\text { absolutely no attention to the } \\
\text { pros and cons, or whether } \\
\text { surgery aligns with his personal } \\
\text { values and what he really } \\
\text { wants. He simply says 'yes' to } \\
\text { the surgery on an impulse. }\end{array}$ \\
\hline $\begin{array}{l}\text { If he had not resisted his initial } \\
\text { impulse and made a decision } \\
\text { based on thinking things } \\
\text { through properly, Marvin } \\
\text { would have said 'no', despite } \\
\text { surgery being the right choice } \\
\text { for him. }\end{array}$ & $\begin{array}{l}\text { If he had resisted his initial } \\
\text { impulse and made a decision } \\
\text { based on thinking things } \\
\text { through properly, Marvin } \\
\text { would have said 'no', as } \\
\text { surgery is not the right choice } \\
\text { for him. }\end{array}$ & $\begin{array}{l}\text { If he had been able to resist his } \\
\text { initial impulse and make a } \\
\text { decision based on thinking } \\
\text { things through properly, } \\
\text { Marvin would have said 'no', } \\
\text { as surgery is not the right } \\
\text { choice for him. }\end{array}$ \\
\hline
\end{tabular}




\begin{tabular}{|c|c|c|}
\hline \multicolumn{3}{|c|}{ PEER PRESSURE } \\
\hline Exercises Capacity & Mere Capacity & Lacks Capacity \\
\hline $\begin{array}{l}\text { Marvin's friends are really } \\
\text { pushy and opinionated when it } \\
\text { comes to medical matters, and } \\
\text { they think that it would be } \\
\text { really irresponsible for Marvin } \\
\text { to have the surgery. }\end{array}$ & $\begin{array}{l}\text { Marvin's friends are really } \\
\text { pushy and opinionated when it } \\
\text { comes to medical matters, and } \\
\text { they think that it would be } \\
\text { really irresponsible for Marvin } \\
\text { not to have the surgery. }\end{array}$ & $\begin{array}{l}\text { Marvin's friends are really } \\
\text { pushy and opinionated when it } \\
\text { comes to medical matters, and } \\
\text { they think that it would be } \\
\text { really irresponsible for Marvin } \\
\text { not to have the surgery. }\end{array}$ \\
\hline $\begin{array}{l}\text { Marvin is an intelligent, able } \\
\text { adult, fully capable of making } \\
\text { decisions for himself: even if } \\
\text { he is under pressure from } \\
\text { others to make a certain choice, } \\
\text { he is still perfectly able to } \\
\text { make his own decision and } \\
\text { resist pressure to do things that } \\
\text { he doesn't want to do or that } \\
\text { aren't right for him. }\end{array}$ & $\begin{array}{l}\text { Marvin is an intelligent, able } \\
\text { adult, fully capable of making } \\
\text { decisions for himself: even if } \\
\text { he is under pressure from } \\
\text { others to make a certain choice, } \\
\text { he is still perfectly able to } \\
\text { make his own decision and } \\
\text { resist pressure to do things that } \\
\text { he doesn't want to do or that } \\
\text { aren't right for him. }\end{array}$ & $\begin{array}{l}\text { Marvin is not able and } \\
\text { intelligent like most adults who } \\
\text { are able to make decisions for } \\
\text { themselves: if he is under } \\
\text { pressure from others to make a } \\
\text { certain choice, he is completely } \\
\text { incapable of making his own } \\
\text { decision and resisting pressure } \\
\text { to do things that he doesn't } \\
\text { want to do or that aren't right } \\
\text { for him. }\end{array}$ \\
\hline $\begin{array}{l}\text { And he does so in this instance. } \\
\text { Although he feels pressure } \\
\text { from his friends to say 'no' to } \\
\text { the surgery, he thinks things } \\
\text { through carefully, and makes } \\
\text { his decision with careful regard } \\
\text { for the pros and cons, and } \\
\text { whether surgery aligns with his } \\
\text { personal values and what he } \\
\text { really wants. Because of this, } \\
\text { Marvin says 'yes' to the } \\
\text { surgery. }\end{array}$ & $\begin{array}{l}\text { But he does not do so in this } \\
\text { instance. Giving in to pressure } \\
\text { from his friends to have the } \\
\text { surgery, he doesn't think things } \\
\text { through even a little bit, and } \\
\text { pays absolutely no attention the } \\
\text { pros and cons, or whether } \\
\text { surgery aligns with his personal } \\
\text { values and what he really } \\
\text { wants. Marvin simply says } \\
\text { 'yes' to the surgery. }\end{array}$ & $\begin{array}{l}\text { So he does not do so in this } \\
\text { instance. Giving in to pressure } \\
\text { from his friends to have the } \\
\text { surgery, he doesn't think things } \\
\text { through even a little bit, and } \\
\text { pays absolutely no attention the } \\
\text { pros and cons, or whether } \\
\text { surgery aligns with his personal } \\
\text { values and what he really } \\
\text { wants. Marvin simply says } \\
\text { 'yes' to the surgery. }\end{array}$ \\
\hline $\begin{array}{l}\text { If he had not resisted the } \\
\text { pressure from his friends and } \\
\text { thought things through for } \\
\text { himself, Marvin would have } \\
\text { said 'no' even though surgery } \\
\text { is what he really wants. }\end{array}$ & $\begin{array}{l}\text { If he had resisted the pressure } \\
\text { from his friends and thought } \\
\text { things through for himself, } \\
\text { Marvin would have said 'no', } \\
\text { as surgery is not what he really } \\
\text { wants. }\end{array}$ & $\begin{array}{l}\text { If he had been able to resist } \\
\text { pressure from his friends and } \\
\text { think things through for } \\
\text { himself, Marvin would have } \\
\text { said 'no', as surgery is not } \\
\text { what he really wants. }\end{array}$ \\
\hline
\end{tabular}




\begin{tabular}{|c|c|c|}
\hline \multicolumn{3}{|c|}{ UNINFORMED } \\
\hline Exercises Capacity & Mere Capacity & Lacks Capacity \\
\hline $\begin{array}{l}\text { While the doctor is explaining } \\
\text { some of the critical risks and } \\
\text { benefits of the procedure, } \\
\text { however, Marvin becomes } \\
\text { distracted by a text message, } \\
\text { and doesn't hear what the } \\
\text { doctor is saying. }\end{array}$ & $\begin{array}{l}\text { Whilst the doctor is explaining } \\
\text { some of the critical risks and } \\
\text { benefits of the procedure, } \\
\text { however, Marvin becomes } \\
\text { distracted by a text message, } \\
\text { and doesn't hear what the } \\
\text { doctor is saying. }\end{array}$ & $\begin{array}{l}\text { Whilst the doctor is explaining } \\
\text { some of the critical risks and } \\
\text { benefits of the procedure, } \\
\text { however, Marvin becomes } \\
\text { distracted by a text message, } \\
\text { and doesn't hear what the } \\
\text { doctor is saying. }\end{array}$ \\
\hline $\begin{array}{l}\text { Marvin is an intelligent, able } \\
\text { adult: he can tell that he } \\
\text { doesn't know enough about the } \\
\text { surgery to make an informed } \\
\text { choice, so he is perfectly } \\
\text { capable of making sure he gets } \\
\text { the information he needs. }\end{array}$ & $\begin{array}{l}\text { Marvin is an intelligent, able } \\
\text { adult: he can tell that he } \\
\text { doesn't know enough about the } \\
\text { surgery to make an informed } \\
\text { choice, so he is perfectly } \\
\text { capable of making sure he gets } \\
\text { the information he needs. }\end{array}$ & $\begin{array}{l}\text { Marvin is not able and } \\
\text { intelligent like most adults; he } \\
\text { is completely incapable of } \\
\text { making informed decisions. So } \\
\text { he is completely unable to } \\
\text { make sure he has the } \\
\text { information he needs, } \\
\text { understand his options } \\
\text { properly, and make an } \\
\text { informed choice. }\end{array}$ \\
\hline $\begin{array}{l}\text { And he does so in this instance. } \\
\text { He tells the doctor he was } \\
\text { distracted, and the doctor } \\
\text { repeats the relevant } \\
\text { information. Now that he has } \\
\text { substantial information about } \\
\text { the procedure, Marvin makes } \\
\text { his decision with careful regard } \\
\text { for the pros and cons, and } \\
\text { whether surgery aligns with his } \\
\text { personal values and what he } \\
\text { really wants. Because of this, } \\
\text { Marvin says 'yes' to the } \\
\text { surgery. }\end{array}$ & $\begin{array}{l}\text { But he does not do so in this } \\
\text { instance. He doesn't tell the } \\
\text { doctor he was distracted, and } \\
\text { the doctor does not repeat the } \\
\text { relevant information. With little } \\
\text { information about the } \\
\text { procedure, he does not make } \\
\text { his decision with regard for the } \\
\text { pros and cons or whether } \\
\text { surgery aligns with his personal } \\
\text { values and what he really wants. } \\
\text { Marvin simply says 'yes' to the } \\
\text { surgery. }\end{array}$ & $\begin{array}{l}\text { So he does not do so in this } \\
\text { instance. He doesn't tell the } \\
\text { doctor he was distracted, and } \\
\text { the doctor does not repeat the } \\
\text { relevant information. With little } \\
\text { information about the } \\
\text { procedure, he does not make } \\
\text { his decision with regard for the } \\
\text { pros and cons or whether } \\
\text { surgery aligns with his personal } \\
\text { values and what he really wants. } \\
\text { Marvin simply says 'yes' to the } \\
\text { surgery. }\end{array}$ \\
\hline $\begin{array}{l}\text { If he had not asked the doctor } \\
\text { to repeat himself because he } \\
\text { didn't know enough about the } \\
\text { surgery to make an informed } \\
\text { choice, Marvin would not have } \\
\text { realized that surgery was right } \\
\text { for him, and he would have } \\
\text { said 'no'. }\end{array}$ & $\begin{array}{l}\text { If he had asked the doctor to } \\
\text { repeat himself because he } \\
\text { didn't know enough about the } \\
\text { surgery to make an informed } \\
\text { choice, Marvin would have } \\
\text { realized that surgery was not } \\
\text { right for him, and he would } \\
\text { have said 'no'. }\end{array}$ & $\begin{array}{l}\text { Marvin is not able and } \\
\text { intelligent like most adults; he } \\
\text { simply can't tell that he doesn't } \\
\text { know enough about the surgery } \\
\text { to make an informed choice, so } \\
\text { he is not capable of making } \\
\text { sure he gets the information he } \\
\text { needs. }\end{array}$ \\
\hline
\end{tabular}




\begin{tabular}{|c|c|c|}
\hline \multicolumn{3}{|c|}{ SUPERSTITION } \\
\hline Exercises Capacity & Mere Capacity & Lacks Capacity \\
\hline $\begin{array}{l}\text { Today is the } 14 \text { th of April. } \\
\text { Marvin is superstitious about } \\
\text { the number } 14 \text { : he thinks that } \\
14 \text { is his unlucky number and } \\
\text { that things that come up on the } \\
14 \text { th of the month are liable to } \\
\text { be bad. }\end{array}$ & $\begin{array}{l}\text { Today is the 14th of April. } \\
\text { Marvin is superstitious about } \\
\text { the number 14: he thinks that } \\
14 \text { is his lucky number and that } \\
\text { things that come up on the } 14 \text { th } \\
\text { of the month are liable to be } \\
\text { good. }\end{array}$ & $\begin{array}{l}\text { Today is the 14th of April. } \\
\text { Marvin is superstitious about } \\
\text { the number 14: he thinks that } \\
14 \text { is his lucky number and that } \\
\text { things that come up on the } 14 \text { th } \\
\text { of the month are liable to be } \\
\text { good. }\end{array}$ \\
\hline $\begin{array}{l}\text { Marvin is an intelligent, able } \\
\text { adult: he is perfectly capable of } \\
\text { distinguishing reasonable from } \\
\text { unreasonable ways of making } \\
\text { decisions and of making } \\
\text { decisions in a reasonable way. }\end{array}$ & $\begin{array}{l}\text { Marvin is an intelligent, able } \\
\text { adult: he is perfectly capable } \\
\text { of distinguishing reasonable } \\
\text { from unreasonable ways of } \\
\text { making decisions and of } \\
\text { making decisions in a } \\
\text { reasonable way. }\end{array}$ & $\begin{array}{l}\text { Marvin is not able and } \\
\text { intelligent like most adults: he } \\
\text { is completely incapable of } \\
\text { distinguishing reasonable from } \\
\text { unreasonable ways of making } \\
\text { decisions and of making } \\
\text { decisions in a reasonable way. }\end{array}$ \\
\hline $\begin{array}{l}\text { And he does so in this instance. } \\
\text { Even though fourteen is his } \\
\text { unlucky number, he thinks the } \\
\text { surgery through carefully, and } \\
\text { makes his decision with careful } \\
\text { regard for the pros and cons, } \\
\text { and whether surgery aligns } \\
\text { with his personal values and } \\
\text { what he really wants. Because } \\
\text { of this, Marvin says 'yes' to the } \\
\text { surgery. }\end{array}$ & $\begin{array}{l}\text { But he does not do so in this } \\
\text { instance. Because fourteen is } \\
\text { his lucky number, he simply } \\
\text { says 'yes' to the surgery. He } \\
\text { doesn't think the surgery } \\
\text { through even a little bit, and } \\
\text { pays absolutely no attention to } \\
\text { the pros and cons, or whether } \\
\text { surgery aligns with his personal } \\
\text { values and what he really } \\
\text { wants. }\end{array}$ & $\begin{array}{l}\text { So he does not do so in this } \\
\text { instance. Because fourteen is } \\
\text { his lucky number, he simply } \\
\text { says 'yes' to the surgery. He } \\
\text { doesn't think things through } \\
\text { even a little bit, and pays } \\
\text { absolutely no attention to the } \\
\text { pros and cons, or whether } \\
\text { surgery aligns with his personal } \\
\text { values and what he really } \\
\text { wants. }\end{array}$ \\
\hline $\begin{array}{l}\text { If he had made this decision in } \\
\text { an unreasonable way by not } \\
\text { thinking it through properly } \\
\text { and instead basing it entirely } \\
\text { on his superstition, Marvin } \\
\text { would not have realized that } \\
\text { surgery was right for him, and } \\
\text { he would have said 'no'. }\end{array}$ & $\begin{array}{l}\text { If he had made this decision in } \\
\text { a reasonable way by thinking it } \\
\text { through properly instead of } \\
\text { basing it entirely on } \\
\text { superstition, Marvin would } \\
\text { have realized that surgery was } \\
\text { not right for him, and he would } \\
\text { have said 'no'. }\end{array}$ & $\begin{array}{l}\text { If he had been able to } \\
\text { distinguish reasonable from } \\
\text { unreasonable ways of making } \\
\text { decisions and had thought this } \\
\text { decision through properly } \\
\text { instead of basing it entirely on } \\
\text { superstition, Marvin would } \\
\text { have realized that surgery was } \\
\text { not right for him, and he would } \\
\text { have said 'no'. }\end{array}$ \\
\hline
\end{tabular}

\section{b. Study 2 measures}

\section{Consent}

Consent 1: The doctor had Marvin's permission to proceed with the surgery.

Consent 2: If the doctor proceeds with the surgery now, he'll be acting without Marvin's consent. 
Consent 3: Marvin's 'yes' didn't count as consent.

Morality: Under these circumstances, it would be morally wrong for the doctor to proceed with the surgery.

Freedom: Marvin freely chose to have surgery.

\section{Manipulation checks}

Rational capacity: Marvin has the ability to make rational decisions.

Rational exercise: Marvin made this particular decision rationally.

Authentic capacity: Marvin has the ability to be true to himself when making decisions.

Authentic exercise: When Marvin said 'yes' to having surgery, he was not being true to himself.

Autonomy capacity: Marvin has the ability to shape his own life freely according to his own values and what is right for him.

Autonomy exercise: The way Marvin made this particular decision expressed an ability to shape his life freely according to his own values and what is right for him.

\section{c. Study 2 attention checks}

\section{Attention Checks, Impulse Condition}

1. Which is correct?

a. Marvin IS able to resist and overcome impulses.

b. Marvin IS NOT able to resist and overcome impulses.

2. Which is correct?

a. Marvin made this particular decision by thinking it through properly.

b. Marvin made this particular decision on an impulse.

3. Which is correct?

a. Having surgery WAS the right choice for Marvin.

b. Having surgery WAS NOT the right choice for Marvin.

\section{Attention Checks, Peer Pressure Condition}

1. Which is correct?

a. Marvin IS able to resist pressure from others and make decisions for himself.

b. Marvin IS NOT able to resist pressure from others and make decisions for himself.

2. Which is correct?

a. Marvin made this particular decision to have surgery based on pressure from his friends.

b. Marvin made this particular decision to have surgery based on thinking it through for himself.

3. Which is correct?

a. Having surgery WAS the right choice for Marvin.

b. Having surgery WAS NOT the right choice for Marvin.

Attention Checks, Uninformed Condition

1. Which is correct? 
a. Marvin WAS ABLE to tell that he didn't have enough information to make an informed choice.

b. Marvin WAS NOT ABLE to tell that he didn't have enough information to make an informed choice.

2. Which is correct?

a. In the end, Marvin made his decision with SUBSTANTIAL information about the surgery.

b. In the end, Marvin made his decision with LITTLE information about the surgery.

3. Which is correct?

a. Having surgery WAS the right choice for Marvin.

b. Having surgery WAS NOT the right choice for Marvin.

\section{$\underline{\text { Attention Checks, Superstition }}$}

1. Which is correct?

a. Marvin IS capable of distinguishing reasonable from unreasonable ways of making decisions.

b. Marvin IS NOT capable of distinguishing reasonable from unreasonable ways of making decisions.

2. Which is correct?

a. Marvin made this particular decision by thinking it through properly.

b. Marvin made this particular decision by relying entirely on superstition.

3. Which is correct?

a. Having surgery WAS the right choice for Marvin.

b. Having surgery WAS NOT the right choice for Marvin.

\section{STUDY 3 STIMULI}

\section{a. STUDY 3 Vignettes by condition}

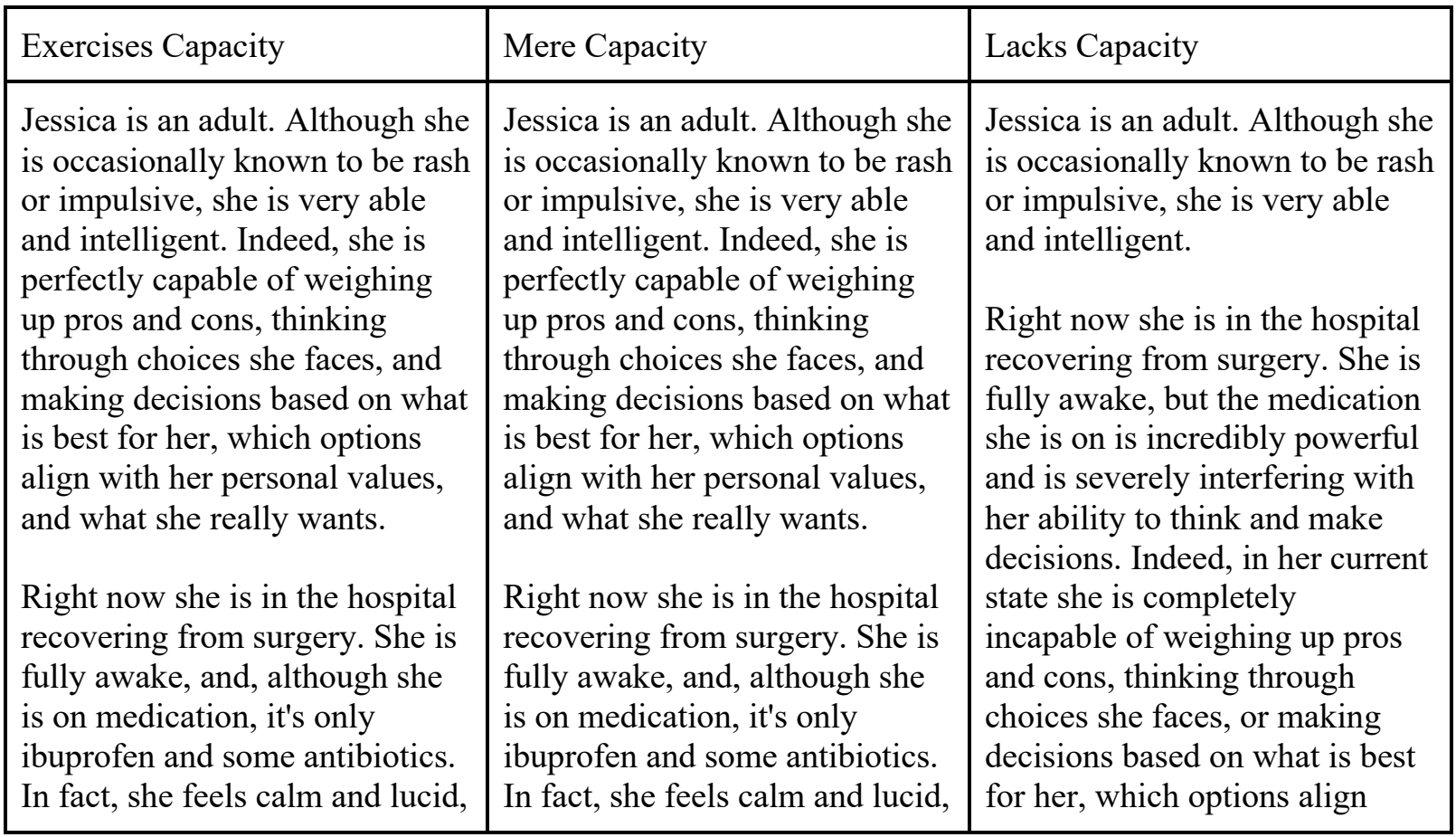


and nothing is interfering in any way with her ability to think or make decisions.

Sam is a friend of Jessica's. He knows that Jessica has a diamond bracelet. Sam knows the bracelet is very precious to Jessica, but he thinks it would sell for a lot of money. He goes to the hospital to ask Jessica if he can sell her bracelet and split the money with her. She is not rash on this occasion: using her ability to make decisions according to her own values and what is best for her, Jessica says 'yes' after thinking things through very carefully, with careful regard for the pros and cons and whether it's what she really wants. and nothing is interfering in any way with her ability to think or make decisions.

Sam is a friend of Jessica's. He knows that Jessica has a diamond bracelet. Sam knows the bracelet is very precious to Jessica, but he thinks it would sell for a lot of money. He goes to the hospital to ask Jessica if he can sell her bracelet and split the money with her. She is rash on this occasion: despite her ability to make decisions according to her own values and what is best for her, Jessica just says 'yes' to the sale without thinking things through even a little bit, and with absolutely no regard for the pros and cons or whether it's what she really wants. with her personal values, or what she really wants.

Sam is a friend of Jessica's. He knows that Jessica has a diamond bracelet. Sam knows the bracelet is very precious to Jessica, but he thinks it would sell for a lot of money. He goes to the hospital to ask Jessica if he can sell her bracelet and split the money with her. Because of her current medicated state, she completely lacks the ability to make decisions according to her own values and what is best for her, so Jessica says 'yes' to the sale without thinking things through even a little bit, and with absolutely no regard for the pros and cons, or whether it's what she really wants.

ALL CONDITIONS continue as follows:

Even though she said 'yes', Sam suspects that Jessica will actually be really sad later about parting with the bracelet. But he just wants to make money for himself. So he takes the bracelet from Jessica and puts it up for sale online.

A woman named Melanie, a complete stranger, sees the ad. She tells Sam that she's interested in buying the bracelet and asks how he came by it. Sam doesn't tell her the real story. Instead, he gives a really convincing story about purchasing it years ago from a jewelry store. Melanie has no reason to doubt his story.

Melanie decides to buy the bracelet. She transfers the money to Sam. Sam receives the payment and then mails Melanie the bracelet, which arrives safely by courier two days later.

\section{b. Study 3 measures}

\section{Consent}

Consent 1: Sam had Jessica's permission to proceed with the sale.

Consent 2: When Sam proceeded with the sale, he was acting without Jessica's consent.

Consent 3: Jessica's 'yes' didn't count as consent.

Morality: Under these circumstances, it was morally wrong for Sam to proceed with selling the bracelet. 
Ownership, binary: Who is the rightful owner of the bracelet? Multiple Choice: Jessica/Melanie

\section{Ownership Rights}

Assume that Melanie could return the bracelet to Jessica and get her money back. Do you agree with the following statement?

Ownership 1: The bracelet does not truly belong to Melanie.

Ownership 2: Even if Melanie was told about the bracelet's true history, it would be morally acceptable for her to keep the bracelet if that's what she wanted to do.

Ownership 3: If Melanie was told about the bracelet's true history, it wouldn't just be nice of her to give the bracelet back to Jessica: it would be her moral duty to give it back.

Ownership 4: Melanie should be forced to return the bracelet.

Ownership 5: A good law would require the bracelet to be returned to Jessica under these circumstances.

Right choice: Saying 'yes' to selling the bracelet was probably the right choice for Jessica at the time.

Freedom: Jessica freely chose to sell her bracelet.

\section{Manipulation checks}

Rational capacity: When Sam asked whether he could sell the bracelet, Jessica had the ability to make a rational decision.

Rational exercise: Jessica made the decision to say 'yes' rationally.

Authentic capacity: Jessica had the ability to be true to herself when making a decision about whether to let Sam sell the bracelet.

Authentic exercise: When Jessica said 'yes' to Sam's selling the bracelet, she was not being true to herself.

Autonomy capacity: Marvin has the ability to shape his own life freely according to his own values and what is right for him.

Autonomy exercise: The way Marvin made this particular decision expressed an ability to shape his life freely according to his own values and what is right for him.

\section{c. Study 3 attention checks}

Capacity Check: Which is correct?

a. Jessica's medication interfered with her ability to think.

b. Jessica's medication DID NOT interfere with her ability to think.

Exercise Check: Which is correct?

a. Jessica said 'yes' WITH regard for whether she really wanted to sell the bracelet.

b. Jessica said 'yes' WITHOUT regard for whether she really wanted to sell the bracelet 